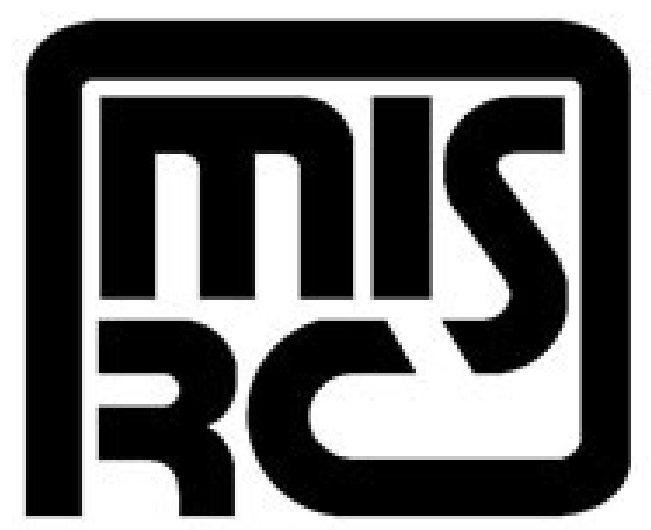

Explaining Variations in Client Extra Costs between Software Projects Offshored to India Author(s): Jens Dibbern, Jessica Winkler and Armin Heinzl

Source: MIS Quarterly, Vol. 32, No. 2, Special Issue on Information Systems Offshoring (Jun., 2008), pp. 333-366

Published by: Management Information Systems Research Center, University of Minnesota

Stable URL: http://www.jstor.org/stable/25148843

Accessed: 28/04/2014 04:33

Your use of the JSTOR archive indicates your acceptance of the Terms \& Conditions of Use, available at http://www.jstor.org/page/info/about/policies/terms.jsp

JSTOR is a not-for-profit service that helps scholars, researchers, and students discover, use, and build upon a wide range of content in a trusted digital archive. We use information technology and tools to increase productivity and facilitate new forms of scholarship. For more information about JSTOR, please contact support@jstor.org.

Management Information Systems Research Center, University of Minnesota is collaborating with JSTOR to digitize, preserve and extend access to MIS Quarterly. 


\section{Explaining VARIATIONS In Client Extra Costs Between SOFTWARE PROJECTS OFFSHORED TO INDIA ${ }^{1}$}

By: Jens Dibbern

Department of Information Systems

University of Mannheim

Schloss, D-68131 Mannheim

GERMANY

dibbern@uni-mannheim.de

\author{
Jessica Winkler \\ Department of Information Systems \\ University of Mannheim \\ Schloss, D-68131 Mannheim \\ GERMANY \\ winkler@uni-mannheim.de \\ Armin Heinzl \\ Department of Information Systems \\ University of Mannheim \\ Schloss, D-68131 Mannheim \\ GERMANY \\ heinzl@uni-mannheim.de
}

\begin{abstract}
Gaining economic benefits from substantially lower labor costs has been reported as a major reason for offshoring labor-intensive information systems services to low-wage countries. However, if wage differences are so high, why is there such a high level of variation in the economic success between offshored IS projects? This study argues that offshore outsourcing involves a number of extra costs for the
\end{abstract}

\footnotetext{
${ }^{1}$ This paper was recommended for acceptance by Associate Guest Editor Erran Carmel.
}

client organization that account for the economic failure of offshore projects. The objective is to disaggregate these extra costs into their constituent parts and to explain why they differ between offshored software projects. The focus is on software development and maintenance projects that are offshored to Indian vendors. A theoretical framework is developed a priori based on transaction cost economics (TCE) and the knowledge-based view of the firm, complemented by factors that acknowledge the specific offshore context. The framework is empirically explored using a multiple case study design including six offshored software projects in a large German financial service institution. The results of our analysis indicate that the client incurs postcontractual extra costs for four types of activities: (1) requirements specification and design, (2) knowledge transfer, (3) control, and (4) coordination. In projects that require a high level of client-specific knowledge about idiosyncratic business processes and software systems, these extra costs were found to be substantially higher than in projects where more general knowledge was needed. Notably, these costs most often arose independently from the threat of opportunistic behavior, challenging the predominant TCE logic of market failure. Rather, the client extra costs were particularly high in client-specific projects because the effort for managing the consequences of the knowledge asymmetries between client and vendor was particularly high in these projects. Prior experiences of the vendor with related client projects were found to reduce the level of extra costs but could not fully offset the increase in extra costs in highly client-specific projects. Moreover, cultural and geographic distance between client and vendor as well as personnel turnover were found to increase client extra costs. Slight evidence was found, however, that the cost-increasing impact of these factors was also leveraged in projects with a high level of required client-specific knowledge (moderator effect). 
Keywords: Offshoring, outsourcing, software application services, transaction cost economics, knowledge-based view, absorptive capacity, cross-cultural study, asset specificity, multiple case study

\section{Introduction}

Offshore outsourcing of information systems has seen considerable growth during the past years, especially in the domain of application services. Aside from getting access to skilled and qualified resources, reaping benefits from substantially lower labor costs has been reported as one of the major reasons for offshoring (Apte et al. 1997; Khan et al. 2003; Rottman and Lacity 2004; Schaaf 2004; Sobol and Apte 1995). Similar to domestic outsourcing, however, there are indications that the expected economic benefits are not always achieved. While realized cost savings through offshore outsourcing may range between 20 and 50 percent, studies also show that in about 50 percent of the cases offshore projects fail to achieve cost savings or that costs actually increase (Hatch 2004; Schaaf 2004). Obviously there are situations where a number of "extra costs" arise in offshore outsourcing that can offset the client's expected cost savings from lower labor costs in low-wage countries (Carmel and Tija 2005, p. 40).

While attempts have been made to identify and categorize extra offshore cost items (Carmel and Tija 2005; Overby 2003), there is still little knowledge about the sources of their magnitude (i.e., how much of these extra costs should be calculated into the business case of a particular offshore project). Whenever different types of extra costs, such as transaction costs (e.g., initiation, contracting, and control costs), were distinguished in previous studies, little attempt was made to explain why those costs may differ between particular offshore projects (Carmel and Nicholson 2005). Variations in project performance were predominantly examined from the vendor rather than the client side. For example, it was found that vendor performance metrics such as project effort, elapsed time, and software rework are contingent on a number of project characteristics such as the use of standardized processes and prior experiences of the vendor personnel (Gopal et al. 2002). Moreover, it is not clear how the offshore outsourcing context (i.e., the fact that an IS function is outsourced to another country) actually influences the economic success of an offshore project. Although some studies identified various types of risks or challenges associated with offshore outsourcing, such as cultural differences, geographic distance, or regulatory/legal differences (Apte et al. 1997; Carmel and Agarwal 2002; Khan et al. 2003; Kliem 2004; Ramarapu and Parzinger 1997), there is still little under- standing about the relationships between these offshorespecific challenges and further economic risks, such as extra costs. The fact that offshore regions, such as China and India, were found to differ in transaction costs (Qu and Brocklehurst 2003), however, clearly indicates that the magnitude of extra costs is influenced by offshore-specific factors.

When examining the emergent literature on IS offshoring, it is also striking that the majority of research has focused on how to best manage offshore projects (Carmel and Agarwal 2001; Gopal et al. 2003; Heeks et al. 2001; Kliem 2004; Krishna et al. 2004; Nicholson and Sahay 2001). While these studies have greatly enhanced our understanding of how to address some of the offshore-specific challenges, little recognition has been given to the alignment of management practices to specific project properties, which may lead to the impression that virtually any type of service can successfully be outsourced offshore if only the appropriate management techniques are applied. This view is in stark contrast to research findings from domestic outsourcing, which emphasize that beyond the downstream importance of managing the relationship with the vendor, the decision on what to outsource has important implications for relationship management practices and outsourcing success (Grover et al. 1996; Lacity and Willcocks 1998).

As offshore outsourcing ${ }^{2}$ is actually a "buy" strategy with a vendor located in a country different from that of the client (Carmel and Tjia 2005, p. 103), research on offshoring can fruitfully build on these insights from research on domestic outsourcing. The most applied theoretical lens to examine the linkage between the properties of IS functions and the economic efficiency of outsourcing has been transaction cost economics (TCE) (Dibbern et al. 2004). The sole recognition of TCE for explaining the conditions of market efficiency, however, has come under scrutiny more recently. In particular, the knowledge-based view (KBV) of the firm has been suggested as a complementary stream of reasoning (Conner and Prahalad 1996; Grant 1996). It acknowledges the fact that knowledge is heterogeneously distributed across firms and that the management of knowledge asymmetries between client and vendor can lead to extra costs for the client organization, independent of vendor opportunism. Accordingly, our study attempts to build on both TCE and KBV to explain variations in extra offshoring costs, expanding both perspectives with offshore-specific factors. The focus of our analysis

\footnotetext{
${ }^{2}$ The decision of "buy versus build" is inherent in any type of offshoring strategy (Carmel and Tjia 2005, pp. $103 \mathrm{ff}$ ). While buy refers to offshore outsourcing or out-tasking to third parties, a build strategy implies ownership of offshore resources, such as in captive centers or subsidiaries. Hybrid arrangements such as joint ventures also exist.
} 
is set on software development and maintenance projects. Both the development and maintenance of software are labor intensive tasks and hence are most likely to be offshored from the portfolio of IS functions (Hirschheim et al. 2004). Having set the focus of this study, our research objective can be summarized by the following research questions:

\section{What types of extra costs may arise for the client in off- shored software projects?}

\section{How and why do these client extra costs vary between offshored software projects?}

In the next section, we will provide the theoretical foundation for studying these research questions. An a priori framework will be developed to serve as a basis for analyzing the extra costs of a number of software projects that are offshored to Indian vendors by a leading German financial services provider. From our theoretical and empirical reflections, we are able to derive a refined theoretical understanding of the composition of client extra costs and their main drivers. Moreover, based on our findings, implications for research are outlined and final conclusions are drawn.

\section{Theoretical Foundation}

The theoretical framework of this study is built on the complementary theoretical perspectives of TCE and KBV. These two theories of the firm are complemented by offshorespecific factors that are derived from existing literature on the international division of labor. Figure 1 presents a graphical illustration of this framework.

The framework essentially suggests that offshore outsourcing is associated with a number of extra costs for the client that go beyond the contract-based payments to the vendor. These extra costs arise for activities such as controlling vendor performance, coordinating project resources, transferring knowledge to vendor personnel, as well as specifying software requirements. Based on TCE and KBV, it is argued that the level of extra costs for the client critically depends on the degree of required client-specific knowledge as well as the vendor's absorptive capacity. Moreover, offshore-specific client-vendor distance may also lead to increased costs on the client side. The influential role of these specific offshore

\footnotetext{
${ }^{3}$ The goal of our study is to explain variations in extra costs between offshored software projects. Therefore, we focus on a comparison of different offshored software projects; we do not intend to compare offshored projects to in-house projects or domestic outsourcing projects.
}

barriers as well as the impact of the vendor's absorptive capacity is influenced (i.e., moderated) by the degree of required client-specific knowledge. The discussion below elaborates upon each of the key constructs and relationships.

\section{Decomposing Client Extra Costs}

Before elaborating on the specific cost categories that arise for the client during the process of offshore outsourcing (research question 1), it is necessary to define the broad term extra costs. Extra costs are defined as all costs in terms of time, effort, and resources spent by the client organization that go beyond the actual payments to the vendor, that is, beyond compensating the vendor's costs plus paying the vendor's profit margin (Carmel and Tija 2005, p. 40). ${ }^{4}$ The payments to the vendor could either be specified in a fixed price contract or accounted for in a time and material contract (Rottman and Lacity 2004). Occasionally, it comes to contract adaptations during an outsourcing relationship, which may lead to additional payments to the vendor. In addition to contract-based payments, however, the client's extra costs for managing an offshore project need to be taken into account. These extra costs can gradually offset the cost savings from lower payments to offshore vendors (see Figure 2; if extra costs increase, cost savings go down or costs may even become higher than before offshore outsourcing).

Quite often, these extra costs are underestimated when it comes to offshoring application services (Carmel and Tija 2005; Overby 2003; Rottman and Lacity 2004). Extra costs for the client can arise for a number of activities. ${ }^{5}$ These activities can be separated into three phases: the pre-contractual phase, the transition phase, and the service delivery phase (see Figure 3). The focus of our study will be on non-contractual costs that arise for the client organization during the transition and delivery phase. As such, the focus is set on the costs for requirements specification and design, knowledge transfer, control, and coordination. An overview of the relevant cost categories and their definitions is presented in Table 1.

\footnotetext{
${ }^{4}$ Extra costs have also been referred to as "remaining or new costs after outsourcing" (Lancellotti et al. 2003, p.134) or they have been labeled as "hidden costs" (Barthélemy 2001; Overby 2003).

${ }^{5}$ It should be noted that the calculation of costs based on the underlying activities of these costs equals the fundamentals of activity-based costing (see Lammers et al. 2004).
} 


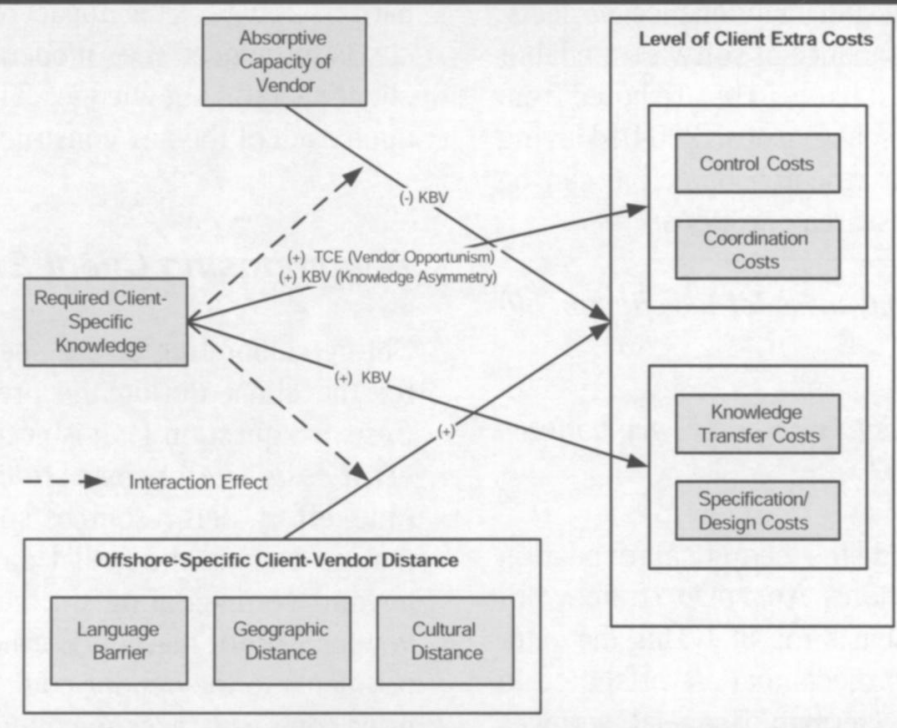

Figure 1. Theoretical Framework

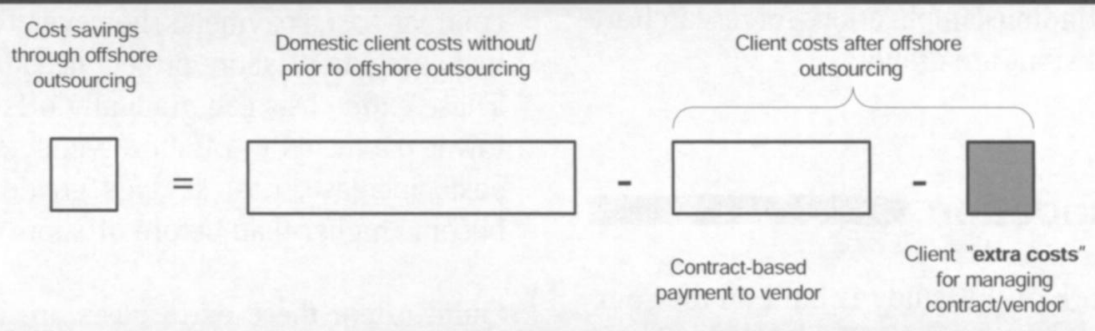

Figure 2. Role of Client Extra Costs in Calculating Cost Savings from Offshore Outsourcing

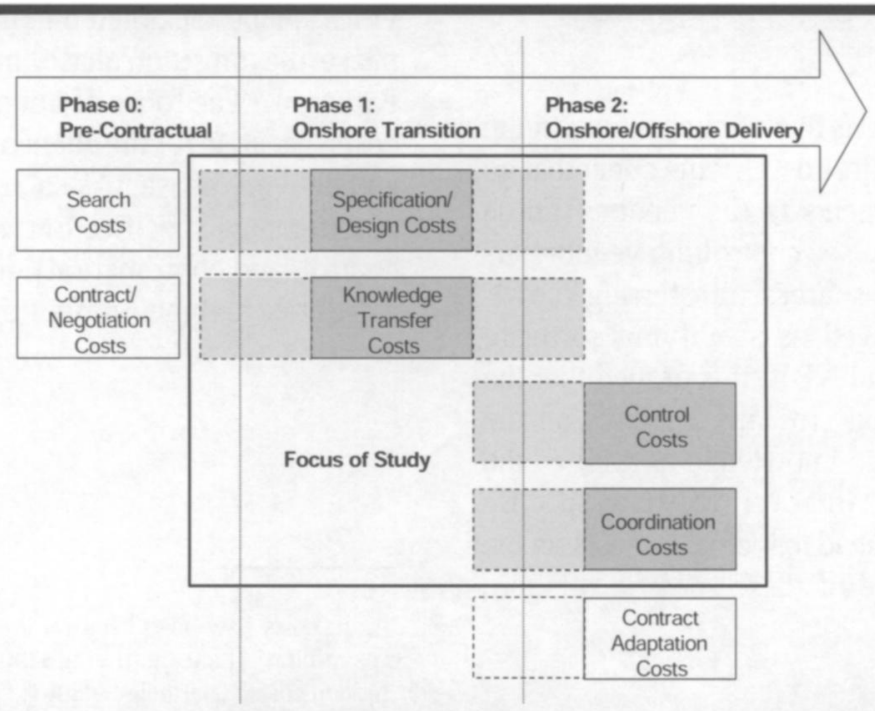

Figure 3. Client Extra Costs in Offshore Outsourcing 


\begin{tabular}{|l|l|l|}
\hline \multicolumn{1}{|c|}{ Table 1. Definition of Extra Cost Categories } & \multicolumn{1}{|c|}{ Definition } \\
\hline \multicolumn{1}{|c|}{ Cost Category } & \multicolumn{1}{|c|}{ Source } \\
\hline Specification costs & $\begin{array}{l}\text { Client costs associated with the process of explaining and defining what } \\
\text { services are required from the system and identifying the constraints on } \\
\text { systems operation and development. }\end{array}$ & $\begin{array}{l}\text { Based on Sommerville } \\
(2004, p .75)\end{array}$ \\
\hline Design costs & $\begin{array}{l}\text { Client costs associated with the "description of the structure of the soft- } \\
\text { ware to be implemented, the data which is part of the system, the inter- } \\
\text { faces between the system components, and, sometimes, algorithms used." }\end{array}$ & Sommerville (2004, p. 76) \\
\hline $\begin{array}{l}\text { Knowledge transfer } \\
\text { costs }\end{array}$ & $\begin{array}{l}\text { Costs associated with the communication of knowledge from the client } \\
\text { organization so that it is learned and applied by the offshore vendor. }\end{array}$ & $\begin{array}{l}\text { Based on Ko et al. (2005, } \\
\text { p. 62) }\end{array}$ \\
\hline Coordination costs & $\begin{array}{l}\text { Costs for integrating and linking together client and vendor resources to } \\
\text { accomplish a collective set of tasks. }\end{array}$ & $\begin{array}{l}\text { Based on Van de Ven et } \\
\text { al. (1976, p. 322) }\end{array}$ \\
\hline Control costs & $\begin{array}{l}\text { Costs for ensuring that the vendor acts and performs in a manner that is } \\
\text { consistent with achieving the desired objectives of the client. }\end{array}$ & $\begin{array}{l}\text { Based on Choudhury and } \\
\text { Sabherwal (2003, p. 292) }\end{array}$ \\
\hline
\end{tabular}

\section{Requirements Specification and Design and Knowledge Transfer Costs}

For understanding these extra costs, it is important to consider the nature of the task that is delegated from the client to the offshore vendor. Software development and maintenance are both labor intensive tasks (Boehm 1987; De Marco and Lister 1987). Both can be characterized as

the processing of knowledge in a very focused way...moving from the knowledge application domain to software architectural and algorithmic design knowledge, and ending in programming language statements (Robillard 1999, p. 92).

In broad terms, the required knowledge that needs to be processed can be separated into two spheres: "(1) knowledge about the application problem domain and (2) technical knowledge through which a software solution is developed" (Tiwana 2003, p. 259; see also Tiwana 2004).

Offshore outsourcing, like domestic outsourcing, implies a contract-based separation of the sources of both types of knowledge (Beath and Walker 1998; Tiwana 2003). The application domain knowledge usually resides on the client side. The client continually produces new application domain knowledge which reflects its constantly changing business requirements. While it is necessary for the client to keep a certain level of technical understanding (e.g., architectural knowledge) when outsourcing an IS function to an external vendor, the majority of the technological knowledge is the responsibility of the vendor. Accordingly, offshore outsourcing brings about the challenge of integrating both types of knowledge (Beath and Walker 1998; Tiwana 2003). Knowledge integration can be achieved in a twofold way (Conner and Prahalad 1996, p. 485). First, the client could transfer his application domain knowledge to the vendor. This would include the transfer of knowledge about the business processes and the user information needs that are to be reflected by the software application. Moreover, the vendor has to gain a solid understanding of the client's existing technical infrastructure including source and target applications of the software application which is to be developed or maintained. Having adopted the necessary client domain knowledge, the vendor would then be able to specify the major functional requirements as well as to perform the design, coding, implementation, and testing. Second, the client could take over the majority of the requirements specification (or even the design). This form of knowledge integration may be referred to as knowledge substitution (Conner and Prahalad 1996, p. 485), since the vendor can work primarily from the detailed specifications (or even software design) of the client without the need to fully understand the application domain background. ${ }^{6}$

Knowledge-substitution is a fundamental response to cognitive limitations, having the effect of economizing on them. Knowledge substitution expands Y's [the vendor's] productive capability without requiring fully concomitant knowledge absorption by Y (Conner and Prahalad 1996, p. 485).

\footnotetext{
${ }^{6}$ Demsetz argues: "Direction substitutes for education (that is for the transfer of knowledge itself)" (Demsetz 1988, p. 157). Specification may also be viewed as a form of "direction" for the subsequent tasks in the software life cycle.
} 
Both activities, knowledge transfer and specification (or even design), require the client to invest time, effort, and resources leading to knowledge transfer and specification costs. They have also been referred to as complementary procedural coordination strategies that need to be balanced out in any interorganizational relationship for product development in general (Sobrero and Roberts 2001), as well as in offshore outsourcing of application development and maintenance in particular (Mirani 2007). Typically, a transition phase is agreed upon in offshore outsourcing. In this transition phase, key vendor personnel stay onshore for a certain period of time to enable the transfer of knowledge from the client to the vendor (Mirani 2007; Tiwana 2004). In addition, the vendor personnel can work out the functional specifications with the client in a collaborative way (Heeks et al. 2001; Krishna et al. 2004). The initial specification of requirements often needs to be modified or complemented during the actual service delivery phase, leading to re-specification costs (Apte 1990). Moreover, additional knowledge transfer is likely to occur during the service delivery phase (Mirani 2007).

\section{Control and Coordination Costs}

Two additional types of extra costs that typically arise in interorganizational relationships such as offshore outsourcing are the costs for coordinating the offshore project and the costs for controlling the vendor's performance. Both control and coordination have been identified as two important activities in the management of software projects, in general (Banker et al. 2006; Choudhury and Sabherwal 2003; Kirsch 1997), as well as in offshore software projects, in particular (Sabherwal and Choudhury 2006). Although the two types of costs are interrelated in that "improved coordination helps in the exercise of control while effective control may improve coordination" (Sabherwal and Choudhury 2006, p. 190), they represent two distinct concepts (Benslimane et al. 2005; Sabherwal and Choudhury 2006; White and Lui 2005).

Control is the mechanism through which the client ensures that the vendor performs adequately. This could be achieved both through output control (e.g., through checking the quality of the software solution provided by the vendor) and behavior control (e.g., through observing how the onshore or offshore personnel of the vendor are actually performing their work) (Eisenhardt 1985; Kirsch 1997; Ouchi 1979). Both activities lead to control costs for the client.

Coordination costs are the costs for integrating and linking together client and vendor resources to accomplish the collective task of software development or maintenance (based on Van de Ven et al. 1976, p. 322). This includes the distribu- tion of work across project members, ensuring that every team member knows how her or his work is related to the work of other team members. Proper procedures and infrastructure must also be available for exchange between the members of the offshore project, including client personnel and onshore and offshore staff of the vendor. Closely related to the notion of coordination - as defined in this study - is the concept of cooperation, which has also been suggested to be different from control (White and Lui 2005). Cooperation captures the necessity of "social integration" that is "necessary in order for partners to combine resources and integrate their activities in the course of undertaking a joint task" (White and Lui 2005, p. 914). Thus, if the client has to invest in team building for social integration between client and vendor staff (Das and Teng 2001), this would be an indication of high cooperation (i.e., coordination costs).

In human systems, on the other hand, the motivations, incentives, and emotions of people are often extremely complex, and understanding them is usually an important part of coordination (Malone and Crowston 1994, p. 91).

Having categorized and defined the types of extra costs that may arise in offshored software projects (research question 1), we will theorize on the drivers of variations in the magnitude of extra costs between different offshored software projects (research question 2). We will do so by deriving propositions from two complementary theoretical perspectives: TCE and KBV.

\section{Transaction Cost Economics}

The roots of TCE date back to Coase (1937) who argued that firms exist because using the market is costly. This basic argument has been picked up by Williamson $(1975,1985)$ in his development of TCE. The main objective of TCE is to identify the conditions under which market governance (e.g., outsourcing) is more cost efficient than governance within the boundaries of a firm (i.e., insourcing).

\section{The main hypothesis out of which transaction cost economics works is this: Firms seek to align trans- actions, which differ in their attributes, with govern- ance structures, which differ in their costs and com- petencies, in a discriminating (mainly transaction costs economizing) way (Williamson 1991, p. 79).}

Thus, the main focus of TCE is on minimizing transaction costs, which can be defined as all costs in terms of time, effort, and money spent, that arise for "planning, adapting, 
and monitoring task completion under alternative governance structures" (Williamson 1981, p. 552). The notion of planning and adapting refers to pre-contractual activities as well as contract adaptations (see Figure 3), which are not the focus of our study. The concept of monitoring, however, is reflected by the concept of control. Accordingly, we will subsequently use the term control costs equally to that of transaction costs. According to TCE, the existence of control costs is based on two fundamental behavioral assumptions. First, it is assumed that economic actors are boundedly rational (based on Simon 1957). Accordingly, contracts can only be settled incompletely since "it is impossible to deal with complexity in all contractually relevant aspects" (Williamson 1981, p. 554). The incompleteness of contracts would not matter if the contractual partners were completely trustworthy ("stewardship behavior," Williamson 1975, p. 26). This, however, is ruled out by a second assumption. It is assumed that some actors behave opportunistically, which means that they cunningly take advantage of opportunities at the expense of others-also referred to as "selfinterest seeking with guile" (Williamson 1981, p. 554). It is assumed that it is hard, or indeed impossible, to anticipate another person's attitude toward opportunism, which likely leads to opportunistic behavior (Williamson 1985, p. 64). Accordingly, control costs arise in order to safeguard against opportunistic behavior of an exchange partner.

The effort for safeguarding against such vendor opportunism, however, is not meant to be constant across any type of market transaction (i.e., outsourcing relationship). Transaction costs are proposed to depend on various contingencies, such as asset specificity, site specificity, uncertainty, and frequency (Williamson 1981). From these four contingencies, asset specificity was found to have the most consistent explanatory power in a wide range of empirical applications of TCE. This was confirmed both in reviews of non-IS disciplines (Rindfleisch and Heide 1997), as well as in a specific literature review on studies of IS outsourcing (Dibbern et al. 2004). Furthermore, the empirical validity of TCE was found to be particularly high when asset specificity was operationalized in terms of human asset specificity rather than physical or technological specificity. In contrast, the impact of uncertainty was found to be very limited, that is, inconsistent (Dibbern et al. 2004; Rindfleisch and Heide 1997). Site specificity appears to be relevant in physical production settings, while frequency has rarely been investigatedpresumably because this would require the observation of transactions over time, which is very demanding to achieve in empirical studies.

This study, therefore, focuses on human asset specificity as the main predictor variable from TCE. Human assets refer to special characteristics of the professionals that are involved in developing and maintaining software applications. In particular, they refer to different kinds of knowledge sets that are required to perform an activity. According to Williamson (1981, p. 563), it is the nature of knowledge that matters when differentiating between highly and less specific human assets. Applied to the IS outsourcing context, human asset specificity may hence be referred to as client-specific knowledge, ${ }^{7}$ the degree to which the development or maintenance work of a software project requires a significant amount of understanding of and knowledge about unique work procedures and business processes as well as unique software systems of the client organization (Beath and Walker 1998; Dibbern et al. 2005). If the provision of an IS function requires knowledge that is very client-specific, the vendor has to invest a lot of time and resources in order to adopt this unique knowledge. The vendor, therefore, has to make a client-specific investment. According to TCE, this necessity increases the vendor's propensity to behave opportunistically, because such a specific investment would prevent the vendor from realizing economies of scale by using the same resources (employees and adopted knowledge) in alternative production scenarios (i.e., with other customers). Opportunistic behavior could, for example, take the form of under-investing in the project or using employees that were contracted for the client in other vendor accounts without informing the client. This behavior could result in low service and product quality (i.e., poor software quality) or project delays (Barney 1999, p. 139). In order to safeguard against opportunistic behavior and its negative consequences, the client would invest in constantly monitoring both the vendor's process of software development and maintenance as well as the output (e.g., by checking the quality of the vendor's functional specifications or software design, as well as intermediary releases or prototypes). This leads to increased control costs.

Complementary to control, the client could increase its coordination effort. As stated earlier, control and coordination are interrelated. Coordination enables control and vice versa (Kumar and Seth 1998). Higher investments into coordination could reduce the vendor's propensity toward opportunism. A number of authors have suggested that trust may serve as an antipode of opportunism (e.g., Chiles and McMackin 1996; Ghoshal and Moran 1996; Joshi and Stump 1999; Noorderhaven 1996). Chiles and McMackin (1996, p. 88) conclude that the "inclusion of the social-context variable of trust in the TCE framework will yield a model with greater predictive validity." As coordination increases the level of

\footnotetext{
${ }^{7}$ Related concepts are context-specific knowledge (Sabherwal and BecerraFernandez 2005) and knowledge specificity (Choudhury and Sampler 1997).
} 
trust between client and vendor personnel, the possibility of opportunistic behavior is reduced (Ouchi 1980, p. 134). This is particularly likely when the client invests in cooperationenhancing activities, such as team building and socializing between client and vendor personnel. Notably, this form of coordination has also been referred to as clan control (Ouchi 1979). It focuses on developing "shared values, beliefs, and goals among members so that appropriate behaviors will be reinforced and rewarded" (Das and Teng 2001, p. 259). Since the threat of opportunistic behavior is conceivably high in cases of high asset specificity (i.e., when a lot of client-specific knowledge is required for the development and maintenance work), coordination costs are expected to increase. It is important to note that the argument is not that clientspecific knowledge leads to more opportunistic behavior, but rather that in the case of high asset specificity, vendor opportunistic behavior leads to more extra costs. This observation leads to the following propositions.

\section{Proposition 1: The higher the level of required client-specific knowledge in an offshored software project, the higher are the client's costs for (a) control and (b) coordination in order to safeguard against the threat and presence of opportunistic behavior of the vendor.}

\section{Knowledge-Based View of the Firm}

The knowledge-based view (KBV) is a theoretical perspective originating from the resource-based view (RBV) of the firm (Grant 1996). Based on the RBV, which views the firm as a collection of productive resources (Barney 1991; Penrose 1959; Wernerfelt 1984), the KBV considers knowledge as the critical input in production and as the primary source of value of the firm (Grant 1996, p. 112). Based on the assumption of bounded rationality, this view concludes that "cognitive limitations prohibit individuals from possessing identical stocks of knowledge" (Conner and Prahalad 1996, p. 478). Since each organization has its unique set of human resources, it follows that each organization possesses a unique repository of knowledge, thus leading to knowledge asymmetry between firms. Accordingly, it has been argued that the vertical boundaries of firms "may be analyzed in terms of relative efficiency of knowledge utilization" (Grant 1996, p. 119).

The explicit consideration of the economic implications of knowledge asymmetries between organizations goes beyond TCE, which assumes that the firm and the market have access to the same input factors and can create the same outputs (Conner 1991, p. 142; Demsetz 1988, p. 164; Williamson 1992, p. 339). Indeed, the KBV of the firm is based on the assumption that under certain conditions activities that require the integration of knowledge from different sources can more efficiently be performed within the boundaries of the firm. "Firms exist because they can more efficiently coordinate collective learning than market organization is able to do" (Fransman 1994, p. 186). In particular, if organizationspecific knowledge is required to perform a task, using the external market becomes increasingly inefficient since an external supplier would first have to adopt this knowledge before being able to perform the task. Transferred to the IS offshoring context, this means that the client effort for transferring knowledge to an external vendor is particularly high if the required knowledge to perform the software development and maintenance work is highly client-specific (see Choudhury and Sampler 1997, p. 36).

In order to compensate for the loss of value in transferring highly specific knowledge, the client may take over more and more of the specification (or even design) and at the same time increase the scope of specification, so that that the vendor is partially released from the challenge of understanding the client's unique business processes and infrastructure (Mirani 2007). This process of knowledge substitution, however, is proposed to be inefficient when highly specific knowledge is involved, since it is difficult to externalize such tacit knowledge (Conner and Prahalad 1996, p. 478). This results in the following propositions, which are complementary to TCE:

\section{Proposition 2: The higher the level of required client-specific knowledge in an offshored software project, the higher are the client's costs for (a) knowledge transfer and (b) specification and design.}

It can also be argued that if a high level of client-specific knowledge is required in a software project, control and coordination costs may increase for the client, independent of the threat or presence of opportunistic behavior of the vendor (Conner 1991; Conner and Prahalad 1996; Foss 1993). Critics of TCE have argued that in many situations the vendor may not be able to afford behaving opportunistically, because "over the long run, the invisible hand [market mechanism] deletes actors who are habitually opportunistic" (Hill 1990, p. 503). Opportunistic behavior may destroy the vendor's reputation for a long time and prevent the vendor from conducting ongoing business with the client (Fama 1980, p. 505).

While TCE argues that transaction costs would be nonexistent in the absence of opportunism, the KBV of the firm holds that there may be situations where knowledge transfer between client and vendor is necessary but difficult to achieve. In the 
case of high knowledge specificity, the vendor may struggle to deliver the expected product or service simply because it lacks the client-specific knowledge. The consequence would be that the client spends a lot of effort constantly monitoring the process and product quality of the vendor. Moreover, if knowledge about idiosyncratic client resources (including business processes and/or software systems) is required, there is often a high level of project uncertainty, both regarding the required inputs to the project (e.g., requirements and amount of resources) as well as the output of the process (e.g., the quality of the software) (Nidumolu 1995). A vast amount of control and coordination is therefore necessary to ensure adequate service and product quality (Choudhury and Sabherwal 2003) in spite of the absence of opportunistic vendor behavior (Conner and Prahalad 1996). Accordingly, the following rival propositions to TCE are put forth:

\section{Proposition 3: The higher the level of required client-specific knowledge in an offshored software project, the higher are the client's costs for (a) con- trol and (b) coordination independent of the pre- sence or threat of opportunistic behavior of the vendor.}

Both propositions 2 and 3 are implicitly based on the assumption that external vendors generally lack client-specific knowledge and have equal capabilities to absorb that knowledge. This, however, contradicts the basic assumption of the KBV that firms generally differ in their resources and capacities. In line with evolutionary theory, a firm can be conceptualized as a bundle of routines and as a historical entity whose productive knowledge is the result of an experiencebased learning process (Nelson and Winter 1982). Since all firms go through different learning processes, they are able to develop distinctive capabilities and identities (Knudsen 1995). Considering that offshore vendors generally differ in their prior experiences, their ability to absorb client-specific knowledge likely varies.

Absorptive capacity reflects the "ability to utilize outside knowledge" (Cohen and Levinthal 1990, p. 128). This capacity, which is also referred to as creativity capacity (Cohen and Levinthal 1990, p. 131), "is largely a function of the level of prior related knowledge" (p. 128). In software development and maintenance projects, prior knowledge means having gained experience in similar projects-ideally with the same customer, the same technology, and the same type of business processes (Ethiraj et al. 2005; Gopal et al. 2002). Thus, if the absorptive capacity of a vendor is low, knowledge transfer costs will likely increase for the client. In a like vein, specification costs will increase in the absence of vendor absorptive capacity, since the client may prefer to take over part of the specification directly, therefore increasing costs. Finally, control and coordination costs as a result of knowledge asymmetry will also decrease with a higher level of absorptive capacity of the vendor. Accordingly, the following effect is proposed:

Proposition 4: The higher the level of absorptive capacity of the vendor, the lower are the client's extra costs.

As noted before, prior experiences are particularly important if there is a high need for absorbing client-specific knowledge, which is the case in particular if a software project requires a high amount of client-specific knowledge. However, even if absorptive capacity is high, extra costs may still arise to a certain extent if very idiosyncratic knowledge has to be adopted by the vendor. That is, the negative impact of vendor absorptive capacity on client extra costs will be weaker as the degree of required client-specific knowledge increases. This moderating impact of asset specificity on the effect of absorptive capacity (proposition 5) is illustrated in Table 2.

\section{Proposition 5: The negative impact of vendor ab- sorptive capacity on client extra costs will be moder- ated by level of required client-specific knowledge.}

\section{Impact of Offshore-Specific Factors}

Offshore outsourcing, as compared to domestic outsourcing, brings about unique challenges. Those challenges may arise from cultural differences (Krishna et al. 2004; Rao 2004), geographic distance (Carmel and Agarwal 2002; Rao 2004) and languages barriers (Apte 1990; Rao 2004; Zatolyuk and Allgood 2004) between the client and the vendor country. Furthermore, time zone differences as well as specific institutional features of offshore countries, such as infrastructure, security, political conditions, and intellectual property regulations within the offshore country, have to be taken into account when entering and managing an offshore outsourcing arrangement (Apte 1990; Hirschheim et al. 2005; Rao 2004; Rottman and Lacity 2004). All of these challenges are offshore-specific because they result from the fact that the vendor is located in a country or geographical region different from that of the client organization. Each of these factors implies a certain type of distance between client and vendor. Thus, taken together, they may be referred to as different categories of offshore-specific client-vendor distance measurers (Carmel and Agarwal 2001; Gopal et al. 2003; Heeks et al. 2001; Kliem 2004; Krishna et al. 2004; Nicholson and Sahay 2001). 
Table 2. Interaction Between Client-Specific Knowledge and Absorptive Capacity

\begin{tabular}{|c|c|c|c|c|}
\hline & & \multicolumn{3}{|c|}{ Degree of Client-Specific Knowledge } \\
\hline & & High & Medium & Low \\
\hline \multirow{3}{*}{$\begin{array}{l}\text { Level of } \\
\text { Absorptive } \\
\text { Capacity of } \\
\text { Vendor }\end{array}$} & High & Medium level of extra costs & $\begin{array}{l}\text { Low to medium level of } \\
\text { extra costs }\end{array}$ & Low level of extra costs \\
\hline & Medium & $\begin{array}{l}\text { Medium to high level of } \\
\text { extra costs }\end{array}$ & Medium level of extra costs & $\begin{array}{l}\text { Low-medium level of extra } \\
\text { costs }\end{array}$ \\
\hline & Low & High level of extra costs & $\begin{array}{l}\text { Medium to high level of } \\
\text { extra costs }\end{array}$ & Medium level of extra costs \\
\hline
\end{tabular}

From these offshore-specific factors, the first three, namely cultural and geographic distance as well as languages barriers, can directly affect the quality and ease of interaction between client and vendor. The most obvious challenges are language barriers (Rao 2004). If the client and the vendor speak different languages, communication becomes difficult. This hampers knowledge transfer between client and vendor and increases the likelihood of false specification due to misunderstandings (Apte 1990). Similarly, control and coordination costs will likely increase, since they rely on effective communication which is aggravated through language differences.

In terms of geographic distance it may be argued that communication technologies, such as video conferencing and e-mail and groupware tools that support virtual collaborative work, increasingly substitute the need for physical presence (Clemons et al. 1993). However, considering the nature of software development and maintenance as social actions, physical meetings are still an issue (Apte 1990; Cramton and Webber 2005; Olson and Olson 2000). This is particularly true if a high amount of firm-specific knowledge is involved. This often requires the transfer of tacit knowledge (e.g., if knowledge about unique business processes needs to be adopted by the vendor). Tacit knowledge is best acquired through a process of socialization (Nonaka 1994) via face-toface meetings (Nonaka and Konno 1998); the same applies to specification tasks. Specification requires a process of externalization where tacit knowledge is codified in the form of functional requirements which then need to be internalized by the software designers and programmers. Again, these processes frequently require socializing action between client and vendor personnel (Scarbrough 1998). Geographic distance makes such face-to-face meetings more difficult and costly, which may increase extra costs.

Finally, cultural distance can increase information acquisition costs (Kogut and Singh 1988) and hence increase the cost for all processes where information exchange is required. Cultural distance may be broken down into two components. Basically, cultural differences refer to the extent to which the members of two distinct groups (such as client and vendor personnel from different countries) differ on one or more cultural dimensions, that is, their shared values, norms, beliefs and assumptions that help them organize and structure the world (based on Roberts and Wasti 2002, p. 545). These shared norms and values of a social group serve as generally accepted patterns of behavior and hence influence the behavior of the members of a social group (Keller 1982, $\mathrm{p}$. 117; Murdock 1940, p. 366). Accordingly, culturally affected behavioral differences or clashes may be observed when two cultural groups work together, as is the case in offshore outsourcing. Case studies on offshoring from Anglo-American countries to India, for example, indicate that opposing attitudes toward authority, hierarchy, and power may cause differences in criticism and feedback behavior between client and vendor personnel (Heeks et al. 2001, p. 57; Krishna et al. 2004, p. 65; Nicholson and Sahay 2001, p. 36). These culturally induced differences in the behavior of the offshore vendor necessitate costly counterreactions by the client, such as increased specification effort for avoiding misunderstandings on the vendor side, increased effort for knowledge transfer, more control effort for uncovering misunderstandings early on in the process, and increased coordination effort for enabling and ensuring smooth communication and interaction. ${ }^{8}$ This leads to the following proposition:

\footnotetext{
${ }^{8}$ The direct impact of cultural distance on cost add-ons is consistent with previous literature that examined the moderating link of cultural differences on the relationship between asset specificity and low as opposed to high control modes in foreign investments (Erramilli and Rao 1993; Gatignon and Anderson 1988). In these studies, it was argued that cultural differences increase the information acquisition costs in monitoring and coordination which influence the firm's propensity toward low versus high control modes in foreign countries.
} 


\section{Proposition 6: Offshore-specific client-vendor distance due to cultural differences, geographic distance and languages barriers increases the level of extra costs for the client.}

The client's increase in extra costs due to offshore-specific distance between client and vendor, however, may not be similar in all offshored software projects. In projects where little direct interaction between client and vendor personnel is needed, cultural differences, geographic distance, and language differences may not be a large issue. This is particularly likely if little client-specific knowledge is required by the offshore vendor. Accordingly, the following moderating impact of client-specific knowledge is proposed:

\section{Proposition 7: The impact of distance in culture, geographic location, and language between client and vendor on the level of client extra costs is higher in software projects that require a high level of client-specific knowledge.}

Institutional differences will not be factored into our theoretical frame. These differences include factors such as legal differences or political stability. Since these factors play a particularly important role for contracting or vendor/country choice, rather than for the actual service delivery, they will not be further considered for this study. As far as knowledge about legal systems and regulations of the client country is concerned, this should be captured by the notion of absorptive capacity.

\section{Research Methodology}

For scrutinizing the theoretical framework on extra costs, a multiple case study approach was chosen (Miles and Huberman 1994; Stake 2006; Yin 2003). This approach seemed to be particularly appropriate for answering our main research questions on how and why extra costs differ between offshored software projects (Benbasat et al. 1987; Yin 2003).

The utilization of the case research methodology follows a widely recognized positivist research approach which intends to provide valuable insights into proposed interactions (Dubé and Paré 2003). The testing of a priorispecified propositions is not meant to imitate a survey-based procedure where the objective is to gather as many data points as possible for each variable of the theoretical model in order to increase the statistical generalizability across a larger population (sampling logic, Yin 2003, p. 48). Rather, the objective of the chosen multiple case study approach is to treat each case as a separate test of the theoretical frame in order to achieve an analytic generalization of our model (Yin 2003, p. 32) in which previously developed theory is used as a template that will be compared against the empirical results of the case studies. In this context, the generalizability will be achieved through replication logic in which each case is comparable to a new experiment.

Due to the fact that the constructs and relationships would have been difficult to access in a quantitative manner, the case study approach was deemed particularly appropriate for examining the theoretical frame. This is particularly true for the dimensions extra costs and cultural distance. While it may have been possible to ask respondents of client organizations to estimate the amount of time spent for activities such as knowledge transfer or specification, an approach that does not force respondents into prespecified dimensions, but rather allows for the importance of each dimension to emerge from the analysis and interpretation of the respondents' epilogues and statements about problems, difficulties, and extra effort that they experienced during the offshore endeavor, was preferred (Miles and Huberman 1994, p. 213). The qualitative approach also left room for theory extension in an exploratory manner through identifying the underlying issues and themes of broadly defined constructs such as cultural distance as well as for identifying additional constructs that may complement the original framework (e.g., Brown 1997). ${ }^{9}$

\section{Sampling and Data Collection}

A purposeful sampling strategy was pursued in order to stay in line with the research objectives and the multiple case study design (Quinn Patton 2002). In order to control for potential bias of organizational culture (Hofstede 1980), a single research site was chosen which represents a Germanbased internationally operating financial services provider with several years of experience with both domestic and offshore outsourcing. For reasons of anonymity, this organization is named FINANCE. Together with two top management representatives of FINANCE that are responsible for the firm's organization-wide offshore strategy, six projects were

\footnotetext{
${ }^{9}$ Ideally, any theory building attempts from case studies should be unbiased by a priori theoretical perspectives or propositions (Eisenhardt 1989). However, in our study we thought to combine the merits of a theory testing with a theory building approach in the same spirit in which it is proposed as useful to combine positivist with interpretive approaches when studying organizational phenomena (Cavaye 1996; Lee 1991). This dual approach is consistent with the multiple case study analysis procedure: "In either approach [inductive or deductive], the initial version [causal network or theoryl is amended and refined as it is tested against empirical events and characteristics" (Miles and Huberman 1994, p. 155).
} 
selected from a database of the company's sourcing management unit. To increase homogeneity and comparability between the projects, the projects were required to fulfill the following criteria:

- only non-captive offshore projects with Indian vendors

- only ongoing projects that were initiated at around the same time

- only projects with approximately the same size

- only projects that were organized similarly, in that a combination of onsite and offshore presence of the vendor was agreed in the contract

The projects (i.e., cases) were chosen for enabling theoretical and literal replications (Yin 2003, p. 47). In order to ensure theoretical replication, at least two projects with high extra costs and two projects with relatively low extra costs were included. The perceived overall economic success of the projects from the perspective of top management representatives were used as an initial approximate value for the overall level of extra costs in each project. Each group of projects could then be used for literal replication by examining whether projects with the same level of extra costs showed the same theoretically proposed conditions. This selection procedure resulted in six offshore projects with Indian vendors (three software development and three maintenance projects). An overview of the projects is provided in Table 3 .

In order to obtain a comprehensive picture of the offshore outsourcing projects and to avoid key informant bias (Kumar et al. 1993), we followed a multiple informants design involving key members of each project (Miles and Huberman 1994; Yin 2003). We interviewed several stakeholders of each project: the project manager, one or two team members (from the client team), at least one member from the vendor's team (onsite coordinator, relationship manager, or offshore coordinator), and also involved process owners (business responsibles) wherever possible. The interviews were based on interview guidelines with semi-structured, open-ended questions, including questions about general project information as well as questions regarding the constructs of our theoretical framework. The interview guidelines were tailored to the different roles that the interviewees had in the projects. A high-level interview guideline is provided in Appendix B. In total, 27 semi-structured interviews were conducted by the first author and a research scholar. The interviews were openended and took between 1 and 3 hours. Most interviews were approximately 2 hours in length. The interview language was German for all FINANCE interviewees (except for one project manager with a Spanish background) and English for all vendor interviewees. All interviews were face-to-face, except for one interview with an offshore project leader, which took place via conference call to India. Table 4 provides an overview of the projects and the corresponding interviewees.

\section{Data Analysis Procedure}

All interviews were tape-recorded and transcribed. The transcripts from the 27 interviews were aggregated into a case protocol which comprised 198,996 words and 225 pages of text. The projects were encoded and structured using the software NVivo. The coding procedure was done as follows: First, in order to mitigate potential bias, the second author who had not taken part in the interviews read and coded the interview transcripts by identifying text passages that included information about the constructs of the theoretical framework. This process resulted in a table of 285 text passages and 348 codings since some of the citations provided information about more than one particular dimension. A new construct, "vendor personnel turnover," emerged as an important theme throughout the process of data collection and analysis. It represents an additional vendor characteristic that influences extra costs and hence was incorporated into our framework in an exploratory manner. ${ }^{10}$ Following the coding by the second author, the first author likewise coded the transcripts. The comparison of the two codings resulted in an average inter-coder reliability of 85 percent according to Holsti (1969). The two coders then examined the mismatched coding and agreed on a final coding matrix that was used for the data analysis. The reasons for mismatches were always very obvious (e.g., in that one coder had simply overlooked an issue within a statement). Only in two cases was the third author called in as a referee.

For the purpose of literal and theoretical replication, the instances of the theoretical constructs were determined for each project whenever possible, for example, for the constructs "required client-specific knowledge" and "level of extra costs" (high, medium, low). This will be shown in detail in the "Case Findings" section and the "Explaining Variations in Extra Costs" section. In order to increase the validity of our coding and data analysis procedure, we aggregated multiple sources of evidence (Yin 2003), that is, multiple citations from different stakeholders were examined to determine whether a construct was rated high, medium, or low. Moreover, we attempted to increase internal validity by not only performing pattern matching between variables but also by considering statements that by themselves included causal linkages (Miles and Huberman 1994, p. 144).

\footnotetext{
${ }^{10}$ High employee turnover has been reported as a challenge of offshoring in previous research (Carmel and Tija 2005; Lewin and Peeters 2006), but we did not anticipate it as having such a significant effect on our costs categories.
} 


\begin{tabular}{|c|c|c|}
\hline & FRONTEND (Development) & CORPORATEPAY (Development) \\
\hline Project description & $\begin{array}{l}\text { One part of a large-scale project encompassing } \\
\text { the reengineering of FINANCE's current account } \\
\text { system. This system was the firm's largest and } \\
\text { most important IT system. The purpose of the } \\
\text { reengineering was to consolidate two systems } \\
\text { into one new system in order to eliminate redun- } \\
\text { dancy, reduce maintenance complexity, and } \\
\text { lower the dependency on a few key people. }\end{array}$ & $\begin{array}{l}\text { Development of a European billing system for } \\
\text { high value payments of corporate customers. } \\
\text { This system enabled the business unit to bill } \\
\text { their corporate customers with flexible condi- } \\
\text { tions, for example, multitier conditions or } \\
\text { rebates. }\end{array}$ \\
\hline Contract & Fixed price & Fixed price \\
\hline $\begin{array}{l}\text { Resources } \\
\text { (onsite/offshore) }\end{array}$ & $\begin{array}{l}\text { Transition: } 2 / 0 \text { (client), } 6 / 0 \text { (Indian vendor), 2/0 } \\
\text { (German vendor) } \\
\text { Delivery: } 2 / 0 \text { (client), 2/5 (Indian vendor) }\end{array}$ & $\begin{array}{l}\text { Transition: } 1 / 0 \text { (client), } 6 / 0 \text { (Indian vendor) } \\
\text { Delivery: } 1 / \text { temporarily several developers } \\
\text { (client), 0/6 (Indian vendor) }\end{array}$ \\
\hline Quality issues & Yes (lower quality than expected) & Yes (lower quality than expected) \\
\hline \multirow[t]{2}{*}{ Client extra costs } & High & High \\
\hline & WEBPORT (Development) & INTERCHANGE (Maintenance) \\
\hline Project description & $\begin{array}{l}\text { Development of a financial portal by two } \\
\text { vendors. A German vendor was responsible for } \\
\text { the business requirements analysis while an } \\
\text { Indian vendor took over design, coding, and } \\
\text { testing. The portal to be developed was meant } \\
\text { to provide information about capital market } \\
\text { products for corporate customers. }\end{array}$ & $\begin{array}{l}\text { Maintenance and support of a legacy payment } \\
\text { platform for domestic and cross border pay- } \\
\text { ments. The software realized conversion ser- } \\
\text { vices for high value and bulk payments. First, it } \\
\text { was decided to offshore only the testing of that } \\
\text { application, but later on, the entire maintenance } \\
\text { and support operation was handed over to the } \\
\text { same vendor. }\end{array}$ \\
\hline Contract & Fixed price & Fixed price \\
\hline $\begin{array}{l}\text { Resources } \\
\text { (onsite/offshore) }\end{array}$ & $\begin{array}{l}\text { Transition: } 3 / 0 \text { (client), 3/0 (Indian vendor), 5/0 } \\
\text { (German vendor) } \\
\text { Delivery: } 3 / 0 \text { (client), 1/20 (Indian vendor), 3/0 } \\
\text { (external German consultants) }\end{array}$ & $\begin{array}{l}\text { Transition: } 7 / 0 \text { (client), 3/0 (Indian vendor), 4/0 } \\
\text { (external German consultants) } \\
\text { Delivery: 7/0 (client), 3/12 (Indian vendor), 2/0 } \\
\text { (external German consultants) }\end{array}$ \\
\hline Quality issues & Yes (lower quality than expected) & Yes (lower quality than expected) \\
\hline \multirow[t]{2}{*}{ Client extra costs } & Medium - low & Medium - high \\
\hline & SUBSIDPAY (Maintenance) & CORPACCESS (Maintenance) \\
\hline Project description & $\begin{array}{l}\text { Maintenance and support of a software package } \\
\text { that ensured the bulk payment processing in } \\
\text { one of the European subsidiaries. The applica- } \\
\text { tion processed transactions for local clearing } \\
\text { procedures (i.e., credit orders and direct debits). } \\
\text { The core product was a U.S. standard software } \\
\text { that was significantly enhanced and customized } \\
\text { for the needs and requirements of the firm. }\end{array}$ & $\begin{array}{l}\text { Maintenance of two of the main applications } \\
\text { regarding electronic payments processing for } \\
\text { corporate customers which was previously } \\
\text { outsourced domestically. One system realized } \\
\text { the customer access, while the other enabled } \\
\text { the customer administration. }\end{array}$ \\
\hline Contract & Fixed price & Time and material \\
\hline $\begin{array}{l}\text { Resources } \\
\text { (onsite/offshore) }\end{array}$ & $\begin{array}{l}\text { Transition: } 3 / 0 \text { (client), 9/0 (Indian vendor) } \\
\text { Delivery: } 3 / 0 \text { (client), 0/8 (Indian vendor) }\end{array}$ & $\begin{array}{l}\text { Transition: } 1 / 0 \text { (client), 6/0 (Indian vendor) } \\
\text { Delivery. 1/0 (client), 2/5 (Indian vendor) }\end{array}$ \\
\hline Quality issues & $\begin{array}{l}\text { Yes (lower quality as compared to in-house } \\
\text { maintenance) }\end{array}$ & No \\
\hline Client extra costs & Medium - high & Low \\
\hline
\end{tabular}




\section{Table 4. Overview of Projects and Interviewees}

\begin{tabular}{|l|c|c|c|c|c|c|}
\hline \multirow{2}{*}{$\begin{array}{c}\text { Projects } \\
\text { Interviewees }\end{array}$} & \multicolumn{4}{|c|}{ Development } & \multicolumn{3}{c|}{ Maintenance } \\
\cline { 2 - 7 } & FRONTEND & CORPORATEPAY & WEBPORT & INTERCHANGE & SUBSIDPAY & CORPACCESS \\
\hline $\begin{array}{l}\text { Project } \\
\text { manager }\end{array}$ & 2 & 1 & 1 & 1 & 1 & 1 \\
\hline $\begin{array}{l}\text { Team } \\
\text { member }\end{array}$ & 1 & 1 & N/A & 1 & 1 & 1 \\
\hline Vendor & 2 & 1 & 1 & 1 & 1 & 2 \\
\hline $\begin{array}{l}\text { Business } \\
\text { responsible }\end{array}$ & 3 & - & 2 & 1 & - & 1 \\
\hline
\end{tabular}

1 = number of interviewees; $-=$ not available for interview; N/A = not applicable (i.e., this role did not exist)

At this point, it needs to be noted that for examining the linkage between offshore-specific client-vendor distance and extra costs, as well as for analyzing the interaction effect with client-specific knowledge, we had to primarily rely on statements by the respondents that explained the interaction between these dimensions. This is due to the fact that only offshore projects from Germany to India were examined and hence there was no externally caused variation in the explanatory constructs "language barrier," "cultural distance," and "geographic distance." Accordingly, no truly literal and theoretical replication logic was applicable for these relationships. Nevertheless, consistent themes emerged from our analysis about the impact of these dimensions on extra costs across the projects.

\section{Results}

\section{Level of Extra Costs}

A first look at the case data revealed that client extra costs were incurred in all of the projects to a certain extent. During the interviews, however, it became clear that the actual amount of time and resources that were required by the client for knowledge transfer, specification and design, controlling, and coordinating were not rigorously and consistently tracked by FINANCE. The business and project managers, for example, had no records of the number of hours per day or week they invested for supporting the vendor personnel.

The time that we invest, what we have provided as an input from the business side - we had days with more than 14, 15, 16 hours of work-are not taken into account. (Business Responsible, WEBPORT)

A business case was calculated as part of the sourcing strategy. However, from a business per- spective, the impact has never been validated. (Business Manager, FRONTEND)

We made our business case, but nobody has paid attention to this business case ever again....We assume that what we have calculated or thought is what comes out at the end. Nobody is doing the tracking. (Project Manager, INTERCHANGE)

We estimated the level of extra costs for each project based on our interview data. In doing so, we first searched for statements about the extent to which the business case of each project was met, resulting in a total of 55 business case related quotes. This data gave us a first estimate of the economic success of the projects. The majority of these quotes clearly indicates that extra costs were largely underestimated by FINANCE, regardless of the method that was used to set up the business cases. This is exemplified by the following quotes:

We had a budget increase, since FINANCE employees had to support the vendor at times when the vendor should have been working things out on their own....The result was that the assumption in the business case that the vendor would do 60 percent of the work turned out to be the other way around, 70 percent FINANCE and 30 percent vendor. (Business Responsible, FRONTEND)

We needed three more people from our side. (Project Manager, CORPORATEPAY)

Apparently, we have to invest more time. And time is money. (Business Responsible, WEBPORT)

Our engagement and commitment is very high. And without this special commitment, this professiona- 


\section{lism and this technical know-how, it would not have been possible. (Project Manager, INTERCHANGE)}

\section{Extra costs were incurred during the set-up phase. (Project Manager, SUBSIDPAY)}

One important additional piece of information is the extent to which the client was satisfied with the quality of the vendor performance (in particular software, i.e., solution quality); as long as the quality had not yet met the client's expectations, the project continued on, surpassing deadlines and creating additional costs related to managing the vendor (see Table 3 ). To elaborate on (i.e., isolate) the actual extra costs of each project, we analyzed the specific statements on costs for knowledge transfer, specification and design, control, and coordination. Examples from the cases are provided in Table 5.

Based on this analysis, authors one and two independently determined the level of extra costs (low, medium or high) for each project, with the third author serving as a referee in case of different classification (only two instances). This resulted in an estimation of extra costs incurred in each case (see Table 6).

In order to increase our confidence level in our base estimate, we performed a simple plausibility check. We counted the number of quotes for each project and cost category (Miles and Huberman 1994, p. 213), divided by the number of total cost-related quotes and the number of interview participants for each project (see Sherif et al. 2006). Vendor interviews were not considered in this calculation, since the vendors' team members could hardly provide information about additional effort that had to be incurred on the client side. This calculation is shown in Table 7.

(1) Frequency. As can be inferred from Table 7, the relative number of quotes for extra costs mostly corresponds with our estimate from the content analysis of the quotes. The projects FRONTEND and CORPORATEPAY show the highest number of quotes, followed by SUBSIDPAY. WEBPORT and INTERCHANGE are in the middle, while CORPACCESS ranks lowest.

(2) Nature of costs. With regard to individual cost categories, the numbers show that costs for coordination and control, as well as costs for knowledge transfer and specification and design, occurred mostly in combination, except for INTERCHANGE, where knowledge transfer was the dominant cost category. Furthermore, two different findings emerged from the counting: In the development project WEBPORT as well as in the maintenance projects INTERCHANGE, SUBSIDPAY, and CORPACCESS, costs were incurred throughout the cost categories in a fairly equal way. In contrast, FRONTEND relied heavily on extra knowledge transfer and specification and design, while in CORPORATEPAY, extra costs for coordination and control were more frequently mentioned. Design costs were mostly incurred in FRONTEND and occurred to a small extent in CORPORATEPAY, WEBPORT, and INTERCHANGE.

Taken together, our baseline estimate was largely met by our follow-up quantitative assessment, which increased our confidence that our estimate of extra costs was valid. Notably, at our final presentation at FINANCE, the project managers also agreed with our appraisal of the level of extra costs in each of the projects, increasing the external validity of our analysis.

\section{Explaining Variations in Extra Costs}

Having identified the level of extra costs in each project, the next question to answer is why these costs varied between the projects (research question 2).

\section{Impact of Required Client-Specific Knowledge}

In the following, we analyze each of the projects with regard to the degree of required client-specific knowledge. Furthermore, we interpret the relation between the degree of required client-specific knowledge and the level of extra costs (Propositions 1,2, and 3). Table 8 exemplifies the classification of the degree of required client-specific knowledge for three of the projects. In line with Dibbern et al. (2005), required client-specific knowledge (i.e., asset specificity) was rated high when the development or maintenance work required knowledge about unique software applications and/or business processes of the client. In contrast, if the application service provision primarily required general technological knowledge (e.g., programming capabilities) or industry knowledge that could be acquired without close interaction with client personnel, the required client-specific knowledge was rated rather low. Moreover, in software reengineering and software maintenance projects, required client-specific knowledge was rated high when the client applications that were taken over by the vendor had a high level of historically grown complexity and if it was difficult to understand the underlying logic of the programming code.

From all projects, the reengineering project FRONTEND turned out to be the one with the highest level of required client-specific knowledge. On the one hand, it required an ex- 


\section{Table 5. Extra Costs}

\begin{tabular}{|c|c|}
\hline Case & Exemplified Quotes \\
\hline \multicolumn{2}{|r|}{ KNOWLEDGE TRANSFER } \\
\hline FRONTEND & $\begin{array}{l}\text { "We have to do an enormous amount of knowledge transfer. Somebody from here would already } \\
\text { have this knowledge." (Team member) }\end{array}$ \\
\hline CORPORATEPAY & "The knowledge transfer was very intense." (Project manager) \\
\hline INTERCHANGE & $\begin{array}{l}\text { "My team members, my German colleagues, are saying, I have to repeat something one hundred } \\
\text { times to the team members, why does the knowledge transfer not happen?" (Project manager) }\end{array}$ \\
\hline SUBSIDPAY & $\begin{array}{l}\text { "We had to explain the same things again and again where we would have expected them to explain } \\
\text { things among themselves." (Team member) }\end{array}$ \\
\hline \multicolumn{2}{|r|}{ SPECIFICATION } \\
\hline FRONTEND & $\begin{array}{l}\text { "They will still need someone from our side to help them consider what the front end could look like... } \\
\text { or what the problems could be." (Business responsible) }\end{array}$ \\
\hline CORPORATEPAY & $\begin{array}{l}\text { "The requirements have to be very precise.... So in the end, we have done most of the work." } \\
\text { (Project manager) }\end{array}$ \\
\hline WEBPORT & "You have to specify precisely what is required or needs to be done." (Project manager) \\
\hline INTERCHANGE & "You have to tell them, please use this template. Do it like this." (Project manager) \\
\hline SUBSIDPAY & "We have to specify and pay attention to many more things." (Team member) \\
\hline \multicolumn{2}{|r|}{ DESIGN } \\
\hline FRONTEND & $\begin{array}{l}\text { "We have to contribute a lot more in order to balance certain deficits, for example, conceptual } \\
\text { deficits." (Team member) }\end{array}$ \\
\hline CORPORATEPAY & "Not only do they need a proof of trust, they also need professional support." (Team member) \\
\hline \multicolumn{2}{|r|}{ VENDOR COORDINATION } \\
\hline FRONTEND & $\begin{array}{l}\text { "Although we are not directly involved in the programming, we have to guide the project very closely, } \\
\text { which is very time consuming." (Business responsible) }\end{array}$ \\
\hline CORPORATEPAY & "We manage the vendor, we allocate the work, and we take care of quality." (Project manager) \\
\hline WEBPORT & $\begin{array}{l}\text { "I have to do a lot of coordination, otherwise things would not happen at all or in the wrong way." } \\
\text { (Project manager) } \\
\text { "There is a lack of effective project management. Given that the vendor has the highest level [CMM] } \\
\text { certification, it is unbelievable that I have to keep track of a project's plan and status myself." } \\
\text { (Project manager) }\end{array}$ \\
\hline \multicolumn{2}{|r|}{ CONTROL } \\
\hline FRONTEND & $\begin{array}{l}\text { "This is a controlling issue. Even though we don't have to, we do a technical implementation in order } \\
\text { to be able to evaluate whether the vendor's solution is right or wrong." (Business responsible) }\end{array}$ \\
\hline CORPORATEPAY & "The vendor needs feedback: What went wrong? And why?" (Team member) \\
\hline WEBPORT & "I am permanently pushing and advising them." (Project manager) \\
\hline INTERCHANGE & $\begin{array}{l}\text { "Documentation, hands on sessions, flying over there, explaining them things, bringing people here, } \\
\text { but at the end of the day, the only reasonable approach apart from all those things, you need more } \\
\text { control and you need more dedication." (Project manager) }\end{array}$ \\
\hline
\end{tabular}




\begin{tabular}{|c|c|c|c|c|c|c|}
\hline & FRONTEND & CORPORATEPAY & WEBPORT & INTERCHANGE & SUBSIDPAY & CORPACCESS \\
\hline Total & high & high & low-medium & medium-high & medium-high & low \\
\hline $\begin{array}{l}\text { Knowledge } \\
\text { transfer, } \\
\text { specification } \\
\text { and design }\end{array}$ & high & medium & medium & medium-high & medium-high & low \\
\hline $\begin{array}{l}\text { Coordination } \\
\text { and control }\end{array}$ & low-medium & high & low-medium & medium & medium & low \\
\hline
\end{tabular}

\section{Table 7. Extra Costs (Number of Quotes)}

\begin{tabular}{|c|c|c|c|c|c|c|}
\hline & FRONTEND & CORPORATEPAY & WEBPORT & INTERCHANGE & SUBSIDPAY & CORPACCESS \\
\hline $\begin{array}{c}\text { (1) Knowledge } \\
\text { Transfer }\end{array}$ & 11 & 1 & 4 & 6 & 4 & 2 \\
\hline (2) Specification & 9 & 2 & 5 & 1 & 3 & 2 \\
\hline (3) Design & 10 & 1 & 1 & 1 & 0 & 0 \\
\hline Total (1) + (2) + (3) & 30 & 4 & 10 & 8 & 7 & 4 \\
\hline $\begin{array}{l}\text { Average } \\
(1)+(2)+(3)^{*}\end{array}$ & 5.0 & 2.0 & 3.3 & 2.7 & 3.5 & 1.3 \\
\hline (4) Coordination & 4 & 4 & 2 & 3 & 2 & 2 \\
\hline (5) Control & 5 & 5 & 4 & 3 & 3 & 3 \\
\hline Total (4) + (5) & 9 & 9 & 6 & 6 & 5 & 5 \\
\hline Average $(4)+(5)^{*}$ & 1.5 & 4.5 & 2.0 & 2.0 & 2.5 & 1.7 \\
\hline Total & 39 & 13 & 16 & 14 & 12 & 9 \\
\hline Average $^{*}$ & 6.5 & 6.5 & 5.3 & 4.7 & 6.0 & 3.0 \\
\hline
\end{tabular}

${ }^{*}$ Average $=$ Total number of quotes/Number of interviewed FINANCE employees

Table 8. Required Client-specific Knowledge

\begin{tabular}{|l|l|l|}
\hline \multicolumn{1}{|c|}{ Case } & Rating & \multicolumn{1}{c|}{ Quote } \\
\hline $\begin{array}{l}\text { FRONTEND } \\
\text { (Development) }\end{array}$ & High & $\begin{array}{l}\text { "Throughout the project, a great amount of business knowledge is needed. We touch a } \\
\text { system that is older than 25 years, where a large number of business rules are } \\
\text { implemented." (Project manager) } \\
\text { "It is a highly complex system. You will not be able to understand it immediately." (Team } \\
\text { member) }\end{array}$ \\
\hline $\begin{array}{l}\text { WEBPORT } \\
\text { (Development) }\end{array}$ & $\begin{array}{l}\text { Medium - } \\
\text { low }\end{array}$ & $\begin{array}{l}\text { "This is a portal. This is a purely technical project, actually. It is more technology than } \\
\text { functionality." (Vendor) } \\
\text { "As I said, you should have a basic knowledge about the data that is displayed. Beyond } \\
\text { that, you are not expected to understand how the rates are calculated." (Vendor) }\end{array}$ \\
\hline $\begin{array}{l}\text { INTERCHANGE } \\
\text { (Maintenance) }\end{array}$ & $\begin{array}{l}\text { Medium - } \\
\text { high }\end{array}$ & $\begin{array}{l}\text { "The complexity we have is very high...I would say, 60 percent of the knowledge was on } \\
\text { the paper and the rest of it was in the people's heads." (Project manager) } \\
\text { "The system is very complex. We have technical people, and we have people who } \\
\text { contribute their knowledge for the business analysis part." (Team member) }\end{array}$ \\
\hline
\end{tabular}


cellent understanding of the two prior systems that were custom-built over a period of almost 30 years; few key persons possessed knowledge about the system and understood the structure. The system reflected business rules that even the business unit itself was not aware of anymore. Although the documentation was enormous, there were still gaps. The system was a unique application that reflected idiosyncratic organizational processes that needed to be understood by the vendor. Transformational business knowledge was needed since the new system should entail additional functionalities that went beyond the original twin system. CORPORATEPAY is in second position with regard to required client-specific knowledge. It primarily required client-specific business knowledge and a very good understanding of the banking market. Moreover, knowledge about FINANCE's idiosyncratic IT landscape was needed for this project. INTERCHANGE was positioned in third place, rated medium-high in terms of required client-specific knowledge. The project started with handing over the testing to the vendor, followed by maintenance and support of a proprietary complex system reflecting processes that are unique to the bank. Although testing methodologies are generic and apply to all types of software, a certain amount of knowledge and understanding about the system's structure and processes was required. For the maintenance task, detailed knowledge about firm-specific processes and application flow was needed. Number four is SUBSIDPAY, also rated medium-high. The project involved the maintenance of a U.S. standard software which was extremely customized to a European subsidiary's needs. Firm-specific processes were thus reflected in the application and therefore needed to be understood by the vendor. The actual maintenance task, however, only included minimal software upgrades and changes. The degree of required client-specific knowledge is therefore rated as medium. CORPACCESS ranks in fifth place, because little unique client knowledge was needed in this project; most of the process flows could be documented. The maintenance work load consisted of technical standard tasks, such as upgrades of the operation system version, the database version, or the programming language version. For these tasks, general technical domain knowledge was required and some unique knowledge about the specific standards that were used in the bank. Accordingly, the degree of required client-specific knowledge of the outsourced tasks is rated medium. Finally, WEBPORT was rated the lowest in terms of required clientspecific knowledge. For this development project, very little organization-specific know-how was needed. For the requirements analysis phase, the external vendor had to bring in knowledge about web portals in the business market and come up with some innovative design ideas. The software did not map any firm-specific process flows. Accordingly, among all outsourced projects to India, this one has the lowest degree of required client-specific knowledge.
Having positioned each project on the required client-specific knowledge continuum, the next step is to examine Propositions 1 to 3 , that is, to determine whether projects with a higher level of required client-specific knowledge actually showed higher levels of extra costs. For this purpose, we created a simple contingency table crossing the two variables ("required client-specific knowledge" and "level of extra costs") (Huberman and Miles 1994). This mapping is illustrated in Figure 4. As can be inferred from Figure 4, this logic largely applies to the projects, supporting our reasoning that a higher level of required client-specific knowledge leads to a higher level of extra costs for the client. Deviations to this logic, as is the case for CORPACCESS, will be discussed in our further analysis.

The next step is to examine the more fine grained TCE logic (Proposition 1) as opposed to that of the KBV (Propositions 2 and 3). First, whether or not control and coordination costs arise for safeguarding against vendor opportunism when asset specificity is high (TCE) or whether they arise due to knowledge asymmetries between client and vendor (KBV) must be examined. Interestingly, we initially could not find any conclusive evidence that coordination and control costs were particularly high due to safeguarding against vendor opportunistic behavior (Proposition 1). The vendor staff was perceived as highly motivated and willing to make the required client-specific investments, even in the two highly client-specific projects FRONTEND and CORPORATEPAY. The problem was that even though the vendor tried very hard, the software quality often did not meet the client's expectations due the vendor personnel's lack of understanding the client requirements as well as the underlying business and application logic. Accordingly, the client invested much more time in error detection and functionality checks than expected, which led to higher control costs. When further examining the sources of the vendor's inability to deliver high quality software without significant client support, we found there was one issue that may be viewed as a form of opportunistic behavior of the vendor: the project staffing management of the vendor. The client often complained about the lack of experience of the vendor personnel (many of the team members came directly from university) as well as the high rate of personnel turnover (both issues will be taken up in detail in the next sections). It seemed that the vendor took little effort in staffing the projects with personnel with the right skill sets or in limiting the rate and the consequences of high turnover. This may be viewed as a form of opportunistic behavior, because the vendor should have informed the client about its problematic staffing situation before the contract was settled. The consequence was that the client eventually invested more time in the coordination of the project. To give an example: In one of the maintenance projects with mediumhigh asset specificity, the project manager complained about 


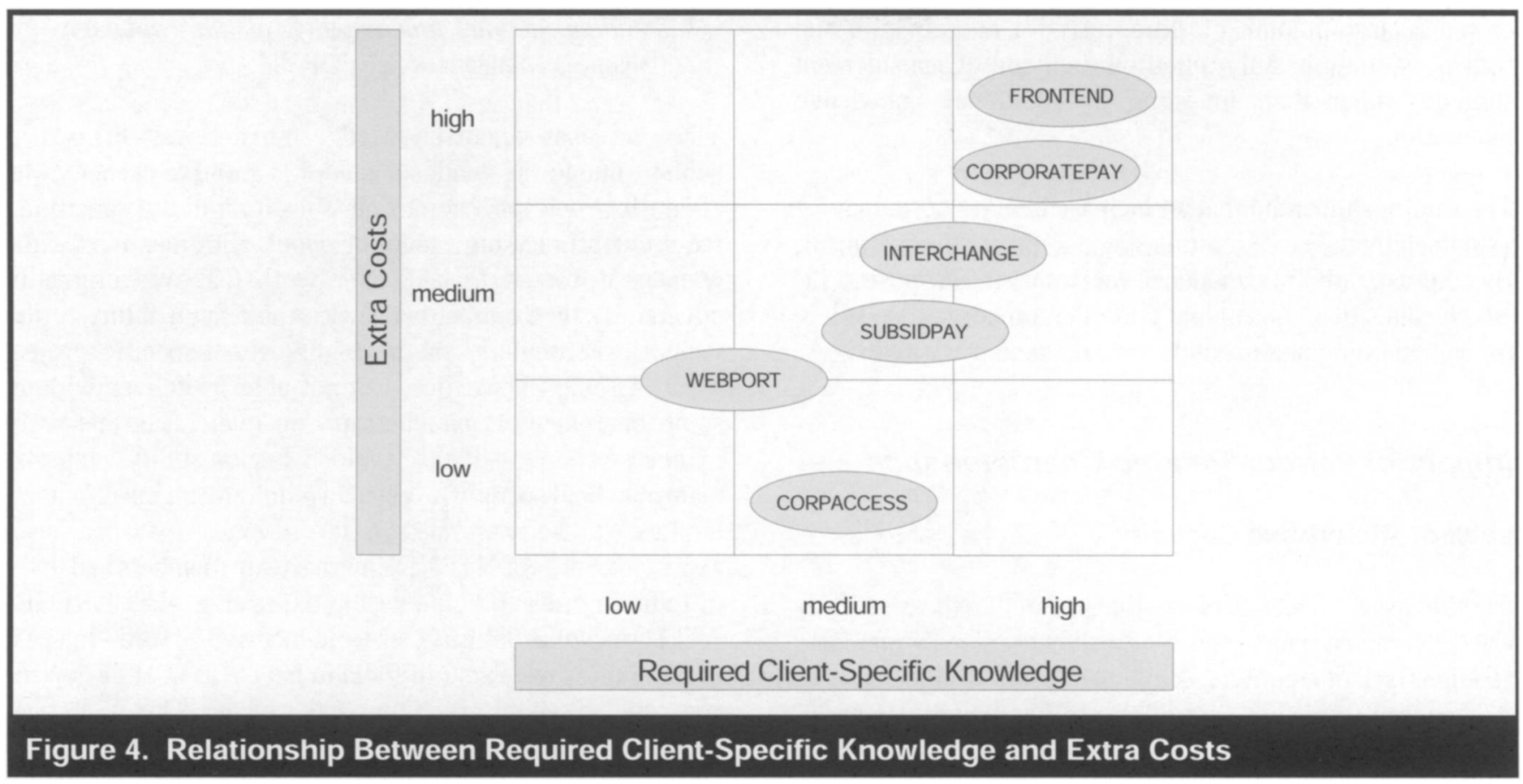

high coordination costs for finding skilled people that are motivated to stay in the project. The project manager put tremendous effort into engaging highly skilled team members and motivating them to stay in the project.

\section{It was a pain in the neck and I was selecting almost every team member, kept looking on their CVs, their experience, the way they react, the way they respond, whether they are serious or not, whether they are professional, whether they are too young people and not committed to this project....So I supervised the project very strictly. (Project Manager, INTERCHANGE)}

Still, an increase in extra costs for control and coordination was observed in the case data for those projects with higher specificity (Proposition 3). As our estimates in Tables 6 and 7 indicate, this holds true for most of the cases. In CORPORATEPAY, a very specific project, management made strong investments in additional coordination and control. They even changed the operating model and decided to regain the lead for all tasks except programming, which was still done in India.

We regained control, that is, we now govern the vendor, we allocate the work and we take care of quality issues. (Project Manager, CORPORATEPAY)
In terms of Proposition 2, there was clear evidence that knowledge transfer and specification and design costs were exceptionally high when client-specific knowledge was required to perform the development and maintenance work (see Tables 6 and 7). The highly specific project FRONTEND illustrates the need to support the Indian vendor in terms of knowledge transfer, specification, and design.

\section{We also thought that the Indian professionals would be able to analyze the program with their tools on their own, and to acquire the business know-how with the help of these tools, but that is also not the case. They highly depend on our help. (Project Manager, FRONTEND)}

Two cases show an exception to this logic: In INTERCHANGE, a lot of effort was mentioned for extra knowledge transfer, but very few statements referred to extra costs due to additional effort for providing specifications for the vendor. This may be explained by the fact that four external consultants were initially hired during the transition phase to develop detailed specifications. Therefore, the challenge for FINANCE was to transfer the knowledge of this rather specific project to the vendor as detailed specifications were already available. CORPORATEPAY provides another exception, since specificity in this project was very high, while knowledge transfer and specification cost were comparably low. As mentioned above, CORPORATEPAY in- 
curred a large amount of extra costs for coordination and control, so they heavily relied on this kind of management strategy rather than investing in additional knowledge integration.

The findings illustrate that an increase in extra costs may be explained by the KBV logic as stated in Propositions 2 and 3. By contrast, only little evidence was found for Proposition 1, which states that control and coordination costs arise solely for safeguarding against opportunistic vendor behavior.

\section{Impact of Vendor-Related Characteristics}

\section{Lack of Absorptive Capacity}

Another aspect which persistently appeared in the case study was a perceived inexperience of the vendors' team members and their lack of creativity. Both were treated as indicators of the vendor personnel's lack of absorptive capacity. Consistent with Proposition 4, inexperience of Indian team members led to higher knowledge transfer costs. Although the Indian vendor of FRONTEND had already worked with FINANCE in other projects, the German project manager realized the lack of domain-specific know-how and experience and hired two German consultants that previously had worked with FINANCE. The support of these two consultants was perceived as very important and helpful for knowledge transfer and specification by the FRONTEND project manager. The initial idea that the offshore vendor would be able to understand the existing applications landscape by using its own reengineering tools was misleading. Additional knowledge transfer was required for understanding the highly specific application logic.

In addition to higher knowledge transfer costs, the Indian vendors' lack of absorptive capacity also lead to increased specification effort. Due to the Indian professionals' lack of creativity and the inexperience of young team members, the requirements specifications had to be very accurate for offshore outsourcing.

I get the desired quality for clearly defined processes. This will be difficult or not achievable for work where I expect creativity from the [Indian supplier] firm. (Project Manager, SUBSIDPAY)

The business unit decided to develop a "storyboard" as we realized: We had to add things so the Indian professionals were able to better understand things, because they didn't ask questions. And if they asked questions it was obvious that they lacked under- standing of the functionality of the webpage. (Business Manager, WEBPORT)

Thus, in cases where knowledge transfer was difficult to achieve due to the vendor's lack of absorptive capacity, the client invested in knowledge substitution by specifying requirements at a high level of detail. In other words, the client was forced to take over work that was originally covered by the contract and hence the responsibility of the vendor. Particularly in the highly client-specific project FRONTEND, the vendor was not able to deliver without some internal team members taking over tasks that were planned to be part of the vendor's responsibility. Internal team members not only invested in requirements specification but also in software design far beyond what had been expected. For FRONTEND, internal team members had to fly to India in order to help execute the testing. In CORPORATEPAY, some design costs were incurred as well. Internal programmers were sent to India to have a look at the source code and to technically support the team. This additional support by the client was necessary because of the vendor's inexperience and lack of required skill sets (i.e., absorptive capacity).
In my opinion, you have to work closely together and observe very closely what work is being done. And this is why the 40:60 [onsite: offshore] model is really hard to achieve. Because in my opinion, we have to contribute a lot more in order to balance certain deficits, for example, conceptual deficits. (Team Member, FRONTEND)

Increased coordination effort was another reaction of the client in responding to the vendor's lack of absorptive capacity. As soon as the client realized how critical it was for the success of the project to have experienced project members on the vendor side, FINANCE felt the need to actively participate in the composition of the vendor's team. This created extra effort (i.e., extra coordination costs).

Because of these difficulties we have to invest in team building, which we underestimated. (Project Manager, FRONTEND)

Control of a project's progress is another important issue. CORPORATEPAY showed that outsourcing the analysis phase and not controlling the results of the design phase may lead to severe problems. Due to the vendor personnel's lack of required business understanding, creativity, and experience, they often failed to fully grasp the business requirements and needs, which led to increased control effort for the client. 
It is not easy to work with the vendor because you have to control each of his steps very closely and you have to make sure that the vendor understands the specified criteria. These are issues that do not come up in this way with a European IT colleague. (Business Manager, FRONTEND)

You need certain control on the deliverables and the way they work and the way they organize themselves....You have to control what they are doing and supervise the results, also the way they have done things....I think the big challenge in this type of project is: you cannot compare the knowledge of a person that has worked on the application of SUBSIDPAY for 10 years with the knowledge one consultant can gain in 6 months or 1 year. (Team Member, SUBSIDPAY)

Prior experiences with the client organization where mostly absent in the projects, except for FRONTEND and CORPACCESS. In CORPACCESS, the vendor's project manager and one team member had formerly worked in a related project with FINANCE, which was perceived as highly valuable by the client project manager:

\section{The project leader had already been part of another FINANCE project. That is, he already had know- how and was familiar with the entire applications landscape and its dependencies. And a colleague was transferred from the other team, which was per- fect because she had a good background regarding the interfaces, and exactly this knowledge was missing in our project. (Team Member, CORP- ACCESS)}

The following two examples illustrate the moderating impact of client-specific knowledge (Proposition 5) as shown in Table 4. In the project CORPACCESS, the relatively high absorptive capacity of some of the project members (see above) contributed to the relatively low extra costs in this project in spite of the fact that a medium level of client-specific business process knowledge was required. In the project FRONTEND, the Indian vendor had also worked with FINANCE previously, but in very different projects (lowmedium absorptive capacity). Still, a large amount of extra costs was incurred in FRONTEND. The system to be reengineered in the project was largely unique and required further transformational business knowledge. Consequently, the vendor needed significant extra support to be able to understand the highly specific software, especially in terms of knowledge transfer, specification, and design.
Overall, the case evidence shows that the offshore vendor's lack of absorptive capacity may lead to extra costs for knowledge transfer, specification, design, coordination, and control, thus supporting Proposition 4. It is striking how the lack of absorptive capacity was associated with all types of extra costs that we had previously considered in our model. The findings also suggest that prior project-related experiences of the vendor led to lower extra costs, but that extra costs remained an issue in the presence of a high level of required client-specific knowledge, thus supporting the interaction effect between asset specificity and absorptive capacity, as stated in Proposition 5.

\section{Personnel Turnover}

A high turnover rate was one aspect that all maintenance project managers and team members invariably complained about, and that also occurred in one development project, CORPORATEPAY.

Turnover is very high. (Project Manager, SUBSIDPAY)

We had trouble because of personnel turnover, people disappeared. (Project Manager, INTERCHANGE)
Almost every year we have a rotation of the current onsite coordinator because they want to return to India. (Project Manager, CORPACCESS)
We struggled with the usual things such as extremely high employee turnover. (Project Manager, CORPORATEPAY)

By contrast, in the development project FRONTEND, turnover was not considered to be too problematic. A possible explanation for this may be that the kind of reengineering work of FRONTEND appeared more interesting and challenging to the vendor's employees and was hence considered a valuable experience.

Our attrition rate is 7 to 8 percent. This is much lower than the Indian average which is about 30 percent. (Project Manager, Indian Vendor, FRONTEND)

In my case, it is always the same people that I deal with. Therefore, I can say that I have really seen quality improvements and advances in learning. (Team Member, FRONTEND) 
The Indian professionals were not shifted to other projects by the vendor. Since FRONTEND showed high extra costs in spite of the low attrition, it is likely that the level of required client-specific knowledge as well as the vendor's lack of absorptive capacity substantially override the effect of low turnover. Such moderating effects may need to be studied more closely in future research.

When employee turnover was present on the side of the Indian vendor, it lead to increased costs for knowledge transfer because in-house team members had to re-explain and specify things for new entrants to the offshore team.

The know-how transfer was intense. However, we were not able to benefit from this at all, because the people involved have left. There was one key person; she obtained valuable knowledge and was gone for good. (Business Manager, CORPORATEPAY)

The coordination effort for integrating a vendor team in a big organization should not be underestimated either.

\section{Every time a new onsite coordinator enters the team, this is related with an incredible amount of adminis- trative work: making sure he has passwords and access to a variety of systems. (Team Member, CORPACCESS)}

From the case evidence, we conclude that personnel turnover is a vendor-related characteristic that may lead to extra client costs. Taking a closer look at the phenomenon of personnel turnover on the vendor side, we saw the need to distinguish between two forms of personnel turnover that may affect offshore outsourcing projects. On the one hand, the offshore vendor himself may move resources from the project to which they were dedicated to another project where they appear to add more value.

That was solved in a clever way by the managers in India. They act in a very pragmatic way, that's for sure. They know how to deploy their personnel in the right way. (Team Member, CORPACCESS)

On the other hand, offshore team members may leave the offshore vendor for good in order to work for a different company or offshore provider. Both forms may be considered as types of opportunistic behavior. Deliberately moving project members to other projects is a practice that was explained by two vendors in the cases of SUBSIDPAY and INTERCHANGE. The vendor organization in SUBSIDPAY provides very experienced team members from so-called centers of excellence. After a certain period, they are replaced by less experienced local team members. The vendor in INTERCHANGE encourages its employees to gain experience in different kinds of projects.

Typically, what happens in those engagements is that these Centers of Excellence provide the initial team which builds the local team and then moves out. (Vendor, SUBSIDPAY)

\begin{abstract}
The point is that you should get used to [personnel turnover]. You cannot ask a person to stay years and years in a project, since he personally wants to gain experience, he wants to go on and move to different kinds of projects. (Vendor, INTERCHANGE)
\end{abstract}

Opportunistic behavior by individuals that leave the vendor organization for good may also cause problems for vendors. The project manager of CORPACCESS explained that Indian onsite coordinators that had spent a year in Germany like to return to India to find a better job due to the qualifications they obtained abroad. Vendors also highlighted the positive side of turnover, because it helps them to get fresh people into the organization.

\section{We need attrition [personnel turnover]. We do not want to avoid attrition.... We need fresh people in the organization. (Vendor, FRONTEND)}

Thus, taken together, employee turnover-when presentcaused extra costs for the client. This turnover can partly be interpreted as opportunistic behavior either at the individual worker or at the vendor level. It should also be noted that, on average, employee turnover was seen as relatively high in India, which is caused by the extremely high volatility and dynamics in the IT labor market of India. There are also some indications that the strong motivation of Indian employees to constantly learn makes it difficult for them to stay in one project, particularly when a project contains routine work and little intellectual challenge.

\section{Impact of Offshore-Specific Client-Vendor Distance}

From the three offshore-specific client-vendor distance metrics, only geographic distance and cultural distance turned out be significant cost drivers for FINANCE. Language differences were found to play a less significant role. Due to the strong international orientation of FINANCE, English was well accepted as a business language and there were few problems in understanding each other in the projects. Only in 
the maintenance projects did the translation of extensive German documentation cause extra effort. Hence, language issues were not further considered in our analysis. In this section, we will illustrate the offshore-specific and vendorrelated characteristics we observed in the cases. We will explain how those characteristics are related to the observed extra costs (Proposition 6). Furthermore, we will analyze the impact of those characteristics in the light of each project's specificity (Proposition 7).

\section{Geographic Distance}

Geographic distance and the resulting time difference caused increased client effort and time for coordination, control, and knowledge transfer. Several interviewees mentioned that complex and tacit issues in particular could be better explained face-to-face and that it otherwise took several rounds of conference calls and e-mail exchange in order to solve them. ${ }^{11}$ This has been confirmed both by vendors and clients.

\section{We do have communication tools, web conferences and things like that in place, however, with complex issues, face-to-face is a lot more efficient. You are able to reach much smoother and simpler solutions. This is what we have realized. (Business Manager, WEBPORT) \\ Instead of sending a slide and explaining difficult things during a telephone conference, it would be a lot easier and faster to explain things on a piece of paper. That is why it is not a bad idea to have one or two people supporting the team onsite in order to clarify things that are difficult to resolve on the phone. (Team Member, FRONTEND)}

As a consequence, offshore personnel were often required to work onsite, which made it easier for the client to explain things and to work out specifications and design issues with the vendor. However, at the same time, client resources were necessary to interact with the vendor personnel onsite, and this again led to additional costs on the client side.

\section{Having them [offshore team members] onsite is associated with an enormous amount of costs. This eroded the original business case. In order to coor-}

\footnotetext{
${ }^{11}$ There was no evidence in the cases that time zone differences caused problems or extra costs. Moreover, in neither of the projects did FINANCE attempt a 24-hour development approach to actually benefit from time zone differences. In contrast, physical (i.e., geographic distance) was a large issue.
}

\author{
dinate all this, I need three additional people at my \\ site. This easily increases costs by 600,000 Euros. \\ (Project Manager, CORPRATEPAY)
}

Geographic distance thus caused additional costs for the client, supporting that part of Proposition 6. Moreover, the problems of long distance were particularly prevalent in the two most client-specific projects FRONTEND and CORPORATEPAY, since in these two projects it was necessary for client personnel to fly to India and support the vendor in the actual implementation and testing by providing very detailed design instructions. This illustrates the moderating impact of required client-specific knowledge on the link between geographic distance and extra costs (Proposition 7). When very client-specific knowledge was required, it was difficult to perform the knowledge transfer through electronic media or to substitute knowledge transfer by writing detailed specifications. The client actually had to collaborate with vendor personnel face-to-face. In FRONTEND, one team member even argued that it is necessary to have both client and vendor personnel working in the same office rather than next door.

\section{Cultural Distance}

Throughout the cases, the team members perceived obvious differences in the German and the Indian working culture. The Indian professionals strongly adhered to hierarchies and tended to implement prescribed specifications with little reflection. This corresponds with well-known findings from previous studies (e.g., Heeks et al 2001; Krishna et al. 2004; Nicholson and Sahay 2001). The Indian team members needed enhanced support and high social collaboration during the knowledge transfer because of the different learning approach and their high conformism. Feedback mechanisms were established in order to recognize misunderstandings at an early stage.

We recognized [that] in the direct contact there will
be no such feedback as "I do not understand." We
have to organize the feedback. That means we have
to establish measures in order to oblige those who
have absorbed information to re-explain it. (Project
Manager, FRONTEND)

Differences in the Indian working culture also increased the specification effort, because of the Indian professionals' high conformism, the requirements specifications had to be very accurate.

After having completed one phase, we had a bad awakening. The functional specifications [for which 
the vendor was responsible] were inspected and a lot of gaps were identified. This is related to the Indian culture.... What they get as an input, they do not question at all...It is the mentality of the Indian professionals to always say yes and to scrutinize. (Team Member, CORPORATEPAY)

We also observed that in terms of coordination and control, the internal team had to compensate for aspects such as the Indian professionals' tendency to not ask questions and clarify issues.

\section{We told them to come up earlier with partial results. We have had the experience that they worked for a long period of time on a document and then we saw that they had moved into a completely different direction. (Team Member, SUBSIDPAY)}

Basically, what they need is feedback: this is the right way, or no, that is the wrong way. (IT Unit Team Member, CORPORATEPAY)

Organizing feedback is especially important in projects where the vendor is required to absorb a lot of client-specific knowledge. Since knowledge substitution by providing directions and detailed specifications may be hard to achieve in highly specific projects, it is essential that the vendor obtains a good understanding of the client's specific application domain and technical context. In the project FRONTEND, where ensuring that the vendor had sufficiently understood the highly client-specific application environment was critical, organizing feedback was especially important (moderation effect).

\section{It is a cultural issue, the Indian team members find it hard to say "I haven't understood, please explain this again "....Many of the presentations and ex- planations we give [during the knowledge transfer] end up on a one-way-street, and misunderstandings only turn out when we ask the vendor to present what he has done.... This is the only way for us to find out how much has actually been understood by the vendor. (Project Manager, FRONTEND)}

The case findings show how cultural distance between German and Indian IS professionals may lead to extra costs for knowledge transfer, specification, coordination, and control, thus supporting Proposition 6. There also is slight evidence for the moderating effect of required client-specific knowledge on increased control and coordination costs due to cultural distance (Proposition 7).
Other interesting findings that emerged from our cultural analysis include a misconception between FINANCE and the vendor about the role of culture.

\section{I think that cultural or linguistic problems are minor issues. Culture is not a problem, never. (Vendor, CORPORATEPAY)}

While the vendor in CORPORATEPAY did not perceive cultural issues as problematic, the FINANCE team members were well aware of cultural disruptions. They did observe, however, that some of the problems due to cultural distance were resolved over time, supporting the trust building process.

\section{Communication between the vendor and the German team members has evolved to be very trustful. The vendor now actively addresses problems. (Team Member, CORPORATEPAY)}

\section{Discussion}

This study was motivated by the need to improve our understanding of why the economic benefits from offshore outsourcing vary substantially between projects. While previous literature has focused mainly on relationship management issues that should help to address the disruptive challenges of offshore outsourcing, this study focuses on the client extra costs that are caused by the constructive response of the client to these challenges. Our study shows that when offshore outsourcing knowledge work, such as the development and maintenance of software applications, extra client costs arise for knowledge integration activities including knowledge transfer on the one hand and knowledge substitution through requirements specification and design on the other. Moreover, extra costs for vendor control and project coordination frequently arise. The level of these extra costs was found to be influenced by three types of factors: (1) the nature of the knowledge work being offshored, reflected by the extent to which client-specific knowledge is required for task performance, (2) the attributes of the vendor, reflected by the vendor's level of absorptive capacity and the rate of employee turnover on the vendor side during the project, and (3) the offshore-specific level of distance between client and vendor, reflected by geographic distance and cultural distance. The preceding relationships were based on the complementary theoretical lenses of TCE and KBV. The consideration of both theories led to a number of theoretical insights that will be discussed next. In order to provide a well-defined context for interpretation, however, we begin with highlighting the major limitations of our study. 


\section{Study Limitations}

There are several limitations to take into account. First and foremost, it should be recognized that the study findings are based on a single-site case study. The findings may be influenced to a certain extent by the overall corporate strategy and culture of the bank. We found a strong identification of the in-house project members with their employer and a strong commitment to work in the company's best interest. This may have increased the perception of cultural differences on the client side at the beginning of the projects. On the other hand, we could not identify any bias through possible connections between the projects. The projects were completely disconnected, the decisions were made independently, and there was little evidence that the management of the project was influenced by other projects. Second, it should be kept in mind that we only studied offshore outsourcing from a German client to Indian vendors. Thus, the offshorespecific factors and their impacts should be treated with caution when studying other client locations or offshore countries. Third, the subjective rating of the variables by the authors may still be an issue, even though procedures for increasing internal and external validly were followed. Moreover, the fact that the researchers that were involved in selecting and analyzing the data were German or educated in Germany poses the risk of cultural bias. A final limitation is a potential bias in the answers of the interview participants. On the client side, we found this concern to be vitiated by the extremely open and even self-critical behavior of the interview participants. This was slightly different on the vendor side, where the interview participants were more reserved, avoiding statements that could shed a negative light on their individual or the company's performance.

\section{Theoretical Implications}

Keeping the limitations outlined in the previous section in mind, our study offers a number of important theoretical contributions.

\section{Disaggregation of Extra Costs}

First of all, our study makes a contribution by disaggregating client extra management costs into more specific costs, including costs for requirements specification and design, knowledge transfer, control, and coordination. The distinction between coordination and control costs contributes to more recent claims of keeping these constructs separate (Sabherwal and Choudhury 2006; White and Lui 2005). It also acknowledges the demand for an explicit assessment of transaction costs and for examining performance implications of governance modes given certain types of contingency configurations (Rindfleisch and Heide 1997, p. 47). The same applies for the consideration of knowledge integration costs including both knowledge transfer and specification (knowledge substitution). These two types of costs extend the very one-sided consideration of transaction costs in TCE. Whether these costs represent participatory production costs of the client (e.g., "participatory design," Malone and Crowston 1994, p. 95) or whether they present a new form of "cognitive transaction costs" (Choudhury 1997) remains an issue of debate. In any case, the results show that the cost categories are highly complementary in nature. Both control and coordination costs as well as the two types of knowledge integration costs were found to arise together, which reinforces previous findings on IT offshore outsourcing (Mirani 2007). When comparing control and coordination with specification and knowledge transfer, however, these costs arose rather as alternative strategies for managing the contract in two of the cases. The disaggregation of extra costs also allows for a better understanding of the theoretical impacts of the sources of extra costs. The examination of the rival lines of argumentation between TCE and KBV on the impact of asset specificity on control and coordination costs deserves special consideration.

\section{Exploring Rival Lines of Argumentation Between Theories: TCE Versus KBV}

While a number of proponents of the KBV have highlighted the fact that asset specificity could lead to market inefficiency independent of the presence of vendor opportunism (TCE), empirical evidence for that view rarely has been provided. As a second contribution, the results of this study show that in projects with a high level of required client-specific knowledge, control and coordination costs can arise-not for safeguarding against opportunistic behavior, but rather for constructively reacting to knowledge asymmetries between vendor and client which are perceivably high in the case of high asset specificity. Moreover, knowledge transfer and specification effort was found to be particularly high in cases where the level of client-specific knowledge was rated high. This does not imply, however, that opportunism is irrelevant in offshore outsourcing. The project staffing management of the vendor could be viewed as a form of opportunistic behavior, which is taken up in the next section.

\section{Theory Extension: Offshore-Specific and Vendor-Related Characteristics May Cause Additional Client Effort}

The third contribution of this study lies in its differentiated analysis of the impact of certain offshore-specific (geographic 
distance, cultural distance) and vendor-related characteristics (absorptive capacity, personnel turnover) on extra costs of offshore application software projects. The cultural distance between Indian and German project members can be traced back to differences in power distance between the two nations. Power distance refers to the extent to which less powerful members of organizations and institutions (like the family) accept and expect that power is distributed unequally. Cross-cultural research has shown that power distance is higher in India than in Germany (Hofstede 1980). In our projects, the high level of power distance in India was reflected in certain behaviors that have also been stressed out in research of Anglo-American origin (Heeks et al. 2001; Krishna et al. 2004; Nicholson and Sahay 2001), such as a high level of conformism (tendency to say yes) as well as obedience to and dependence on rules and obligations among Indian IS professionals. These culturally induced behaviors particularly increased the client's effort for specification, knowledge transfer, and vendor control.

In addition to its high level of power distance, the Indian culture is characterized by a relatively high level of collectivism (Hofstede 1980). This concept stipulates the formation of in-group behavior (Hui and Triandis 1986). Chen et al. (2002, p. 289) have argued that "collectivists typically draw the distinction between those they are personally related to (in-groups) and those they are not (out-groups)." This means that significant effort has to be invested in forming a common knowledge space (ba) (Nonaka and Konno 1998) until the Indian IS professionals-who together may form an ingroup-openly communicate and exchange tacit knowledge with German client personnel. The German team may indeed behave as an in-group as well-either because of the corporate culture or because of the national German culture which also has a slight tendency toward collectivism (Hofstede 1980). Thus, similarity in the cultural dimension collectivism between two cultural groups may not automatically lead to the absence of cultural clashes. Rather, a process of convergence is required to form a collective of two distinct collectivist (in-)groups. The client's effort for enabling such a convergence process causes coordination costs. Such costs together with control and knowledge transfer costs were also found to increase due to the geographic distance between client and vendor.

In addition to the offshore-specific characteristics, two vendor-related offshore features were found to be associated with extra costs on the client side, namely the level of absorptive capacity and the degree of turnover of vendor staff. Our study results showed that from all offshore-specific and vendor-related characteristics, the level of absorptive capacity of the vendor had the widest impact on extra costs. While absorptive capacity may be influenced by different factors (Lane et al. 2006; Malhotra et al. 2005), the results of our study suggest that prior experiences of the vendor personnel with related projects (e.g., similar technology and business processes) were the best indicator for a high level of absorptive capacity. A low level of absorptive capacity leads to increased knowledge transfer effort on the client side and a higher need for detailed specifications. In two of the cases, the client even resigned and took over part of the design work of the vendor because the costs of specification and knowledge transfer were getting too high. In addition, control effort to ensure appropriate software quality increases due to the vendor's lack of creativity in designing innovative and high quality software solutions. These findings go beyond the resource-based reasoning that vendor capabilities are critical for outsourcing success (Goles 2003). In line with the KBV of the firm, our findings suggest that, in addition to existing capabilities such as technical and project management capabilities, the potential to absorb new knowledge is crucial. This is consistent with findings from previous studies which suggest that, in many outsourced projects, knowledge overlaps between client and vendor are required, calling for knowledge exchange processes between both parties (Tiwana 2004).

What also appeared to be a severe problem was the degree of personnel turnover on the vendor side. Once the knowledge transfer which initially occurred onsite was completed, the vendor staff was often either transferred to other clients or left the vendor company for good. This then forced the client to repeat the knowledge transfer with the replacement staff which lead to increased effort. To avoid turnover, the client had to more closely observe the vendor's recruiting and personnel management, which lead to increased control and coordination effort. This finding is consistent with TCE logic that control and coordination costs arise for safeguarding against opportunistic behavior. When personnel leaves for good, this may be viewed as a form of opportunistic behavior at the individual level that negatively affects both the vendor's and the client's costs. When the vendor transfers personnel from one client account to another without informing the client about such intentions prior to entering the contract, this may be viewed as another, more severe form of opportunistic vendor behavior.

\section{Theory Integration: Interaction of Asset Specificity with Vendor-Related and Culture-Related Factors}

The fourth important contribution lies in theory integration by establishing a moderating link between the level of clientspecific knowledge and the impact of both general offshore 
attributes and vendor-related characteristics. The level of client specific knowledge and the vendor's level of absorptive capacity were found to interact in their influence on client extra costs. For example, when both asset specificity was high (i.e., when a lot of unique process and/or software knowledge was required to perform the development and maintenance work) and the vendor's absorptive capacity was low, extra costs were found be particularly high. Additionally, slight evidence was found that the impact of offshorespecific factors (i.e., geographic and cultural distance) on extra costs was leveraged in projects with a high level of required client-specific knowledge. In projects with low asset specificity, such as the development project WEBPORT, little knowledge about unique business processes of the bank was required. Accordingly, a lack of absorptive capacity had no dramatic impact on extra costs. The vendor could mostly draw on standard knowledge about how to build a web interface following the specifications of the client. However, in the development project CORPORATEPAY, where a lot of profound understanding of the idiosyncratic billing processes of the bank was required, the lack of prior experience of the mostly young vendor staff caused a great amount of extra effort on the client side. This effort even increases if the vendor personnel are very hesitant to ask questions and to actively participate in the knowledge exchange process (impact of cultural differences). Moreover, the moderating effect of specificity was shown in the projects CORPACCESS and FRONTEND. In both projects, FINANCE had previous experience with the Indian vendors. As in CORPACCESS, the level of vendor absorptive capacity was high, only little extra costs were incurred despite the project's medium specificity. In contrast, the vendor in FRONTEND had less project related experience (medium) and had difficulty in understanding the highly specific system and business logic. Therefore, the positive impact of the vendor's absorptive capacity was overridden by the negative impact of specificity, thus leading to high extra costs.

\section{Future Research}

Resuming the previous discussion of the study limitations and its findings, a number of implications for future research emerge. First, our single-site research design calls for replication studies that use multiple sites in different industries in order to enrich the insight into the investigated phenomena. Second, it would be necessary to study our framework from the perspective of other cultures both from the client and the vendor side. For example, it would be interesting to examine whether cultural differences are smaller in nearshore arrangements (e.g., between Germany and Russia) and whether this would lead to comparatively lower extra costs on the client side. Third, the formation of cross-national research teams, where researchers from both the client and the vendor country are included, may be a fruitful way to avoid national biases by the researchers and provide better access to informants of foreign countries (Niederman 2005). Fourth, although very demanding, a longitudinal perspective could yield further insight into the phenomena observed. For example, an evolutionary study that examines offshore outsourcing costs over time associated with dynamics in the independent variables could reveal how transaction frequency and organizational learning influence the economic outcome of such projects. A number of interesting questions could be associated with such a design. Are offshore characteristics, such as cultural distance, a persistent phenomenon or do they disappear over time? Do offshore vendors catch up in absorptive capacity? Fifth, while looking at vendor absorptive capacity, another promising research approach would be to look more closely at the client. Which capabilities are necessary at the client organization and is the client able to positively influence the absorptive capacity of the vendor (Erickson and Ranganathan 2006; Gupta and Govindarajan 2000; Tiwana 2004)? How can the knowledge transfer from the client organization to the vendor organization be managed more effectively? In this context, emerging tools for distributed software development or collaborative software development with substantial requirements engineering and knowledge management capabilities could facilitate the client-vendor relationship, reducing extra costs in offshore outsourcing settings (Ciborra and Andreu 2001; Rus and Lindvall 2002). Finally, while our study has only focused on non-captive offshoring arrangements, the question is raised whether captive arrangements, where the client holds part or all of the vendor capital, may help to overcome some of the disruptive challenges of offshoring without leading to significant extra costs on the client side (e.g., for managing employee turnover) (for a recent study of differences between captive and non-captive arrangements, see Levina 2006). Incomplete contracts theory may be promising for examining the effect of ownership on residual control rights over vendor personnel (Hart and Moore 1990).

\section{Conclusion}

Although many companies claim to realize significant cost advantages through offshore outsourcing of IS services, this paper suggests that there is a need for a more profound and differentiated analysis of the economic benefits associated with offshore outsourcing. While labor cost savings are a constituent factor in offshore outsourcing leading to production cost savings, the findings of this paper indicate that additional types of costs may arise when software projects are offshored, which may offset initial labor cost benefits. This 
paper has shown how TCE and KBV may be applied to the offshore outsourcing scenario in order to be able to understand variations in client extra costs between offshored software projects. Extra costs were disaggregated into different categories, and TCE and KBV were extended by including offshore-specific factors such as geographic distance and cultural distance between client and offshore vendor. Despite the limitations that we addressed at the beginning of the discussion, this paper is unique in the sense that it builds upon and extends two complementary theories of the firm that have rarely been jointly applied in the context of outsourcing or offshoring. The study makes a unique contribution to the IS offshoring and outsourcing literature in that it highlights how important it is to recognize the nature of the task being offshored when making the IS offshore outsourcing decision and when searching for appropriate responses in managing the specific challenges of offshore outsourcing. When a high level of client-specific knowledge is required for task performance, the client is unlikely to achieve the desired economic benefits from offshore outsourcing -in particular when the vendor lacks prior experiences in the task domain and hence shows a relatively low level of absorptive capacity. Slight evidence was found that required client-specific knowledge leverages the offshore-specific challenges such as cultural differences and geographic distance. Future research should be encouraged to further examine the implications of various types of contingencies, such as the nature of the task, when searching for efficient strategies to capitalize on the benefits of the global division of labor.

\section{Acknowledgments}

We would like to thank Rudy Hirschheim, René Riedl, Jens Arndt, the associate editor, and four anonymous reviewers for helpful comments on earlier versions of this paper as well as Sanaz Jalayer and Sonja Conchi for their support in conducting the empirical study. We would also like to acknowledge financial support from the German Ministry for Education and Research (BMBF).

\section{References}

Apte, U. 1990. "Global Outsourcing of Information Systems and Processing Services," Information Society (7:4) pp. 287-303.

Apte, U. M., Sobol, M. G., Hanaoka, S., Shimada, T., Saarinen, T., Salmela, T., and Vepsalainen, A. P. J. 1997. "IS Outsourcing Practices in the USA, Japan and Finland: A Comparative Study," Journal of Information Technology (12), pp. 289-304.

Banker, R. D., Kalvenes, J., and Patterson, R. A. 2006. "Information Technology, Contract Completeness, and Buyer-Supplier Relationships," Information Systems Research (17:2), pp. 180-193.
Barney, J. B. 1991. "Firm Resources and Sustained Competitive Advantage," Journal of Management (17:1), pp. 99-120.

Barney, J. B. 1999. "How a Firm`s Capabilities Affect Boundary Decisions," Sloan Management Review (Spring), pp. 137-145.

Barthélemy, J. 2001. "The Hidden Costs of IT Outsourcing," Sloan Management Review (Spring), pp. 60-69.

Beath, C. M., and Walker, G. 1998. "Outsourcing of Application Software: A Knowledge Management Perspective," in Proceedings of the $31^{\text {st }}$ Annual Hawaii International Conference on System Sciences, Los Alamitos, CA: IEEE Press, pp. 666-674.

Benbasat, I., Goldstein, D. K., and Mead, M. 1987. "The Case Research Strategy in Studies of Information Systems," MIS Quarterly (11:3), pp. 369-386.

Benslimane, Y., Plaisent, M., and Bernard, P. 2005. “Investigating Search Costs and Coordination Costs in Electronic Markets: A Transaction Costs Economics Perspective," Electronic Markets (15:3), pp. 213-224.

Boehm, B. W. 1987. “Improving Software Productivity," IEEE Computer (20:9), pp. 43-57.

Brown, C. 1997. "Examining the Emergence of Hybrid IS Governance Solutions: Evidence from a Single Case," Information Systems Research (8:1), pp. 69-94.

Carmel, E., and Agarwal, R. 2001. "Tactical Approaches for Alleviating Distance in Global Software Development," IEEE Software (March/April), pp. 22-29.

Carmel, E., and Agarwal, R. 2002. "The Maturation of Offshore Sourcing of Information Technology Work," MIS Quarterly Executive (1:2), pp. 65-78.

Carmel, E., and Nicholson, B. 2005. "Small Firms and Offshore Software Outsourcing: High Transaction Costs and Their Mitigation," Journal of Global Information Management (13:3), pp. 33-54.

Carmel, E., and Tija, P. 2005. Offshoring Information Technology: Sourcing and Outsourcing to a Global Workforce, New York: Cambridge University Press.

Cavaye, A. L. M. 1996. "Case Study Research: A Multi-Faceted Research Approach for IS," Information Systems Journal (6:3), pp. 227-242.

Chen, C. C., Peng, M. W., and Saparito, P. A. 2002. "Individualism, Collectivism, and Opportunism: A Cultural Perspective on Transaction Cost Economics," Journal of Management (28:4), pp. 567-583.

Chiles, T. H., and McMackin, J. F. 1996. "Integrating Variable Risk Preferences, Trust, and Transaction Cost Economics," Academy of Management Review (21:1), pp. 73-99.

Choudhury, V. 1997. "Strategic Choices in the Development of Interorganizational Information Systems," Information Systems Research (8:1), pp. 1-24.

Choudhury, V., and Sabherwal, R. 2003. "Portfolio of Control in Outsourced Software Development Projects," Information Systems Research (14:3), pp. 291-314.

Choudhury, V., and Sampler, J. L. 1997. "Information Specificity and Environmental Scanning: An Economic Perspective," MIS Quarterly (21:1), pp. 25-53.

Ciborra, C. U., and Andreu, R. 2001. "Sharing Knowledge Across Boundaries," Journal of Information Technology (16:2), pp. 73-82. 
Clemons, E. K., Reddi, S. P., and Row, M. C. 1993. "The Impact of Information Technology on the Organization of Economic Activity: The 'Move to the Middle' Hypothesis," Journal of Management Information Systems (10:2), pp. 9-35.

Coase, R. H. 1937. "The Nature of the Firm," Economica (4), November, pp. 386-405.

Cohen, W. M., and Levinthal, D. A. 1990. "Absorptive Capacity: A New Perspective on Learning and Innovation," Administrative Science Quarterly (35), pp. 128-152.

Conner, K. R. 1991. “A Historical Comparison of Resource-Based Theory and Five Schools of Thought Within Industrial Organization Economics: Do We Have a New Theory of the Firm?," Journal of Management (17:1), pp. 121-154.

Conner, K. R., and Prahalad, C. K. 1996. "A Resource-Based Theory of the Firm: Knowledge Versus Opportunism," Organization Science (7:5), pp. 477-501.

Cramton, C. D., and Webber, S. S. 2005. "Relationships among Geographic Dispersion, Team Processes, and Effectiveness in Software Development Work Teams," Journal of Business Research (58:6), pp. 758-765.

Das, T. K., and Teng, B.-S. 2001. "Trust, Control, and Risk in Strategic Alliances: An Integrated Framework," Organization Studies (22:2), pp. 251-283.

De Marco, T., and Lister, T. 1987. Peopleware, New York: Dorset House Publishing.

Demsetz, H. 1988. "The Theory of the Firm Revisited," Journal of Law, Economics and Organization (4), pp. 141-161.

Dibbern, J., Chin, W. W., and Heinzl, A. 1005. "The Impact of Human Asset Specificity on the Sourcing of Application Services," in Proceedings of the $13^{\text {th }}$ European Conference of Information Systems, D. Bartmann, F. Rajola, J. Kallinikos, D. Avison, R. Winter, P. Ein-Dor, J. Becker, F. Bodendorf, and C. Weinhardt (eds.), Regensburg, Germany, May 26-28, pp. 1645-1658.

Dibbern, J., Goles, T., Hirschheim, R. A., and Jayatilaka, B. 2004. "Information Systems Outsourcing: A Survey and Analysis of the Literature," The DATA BASE for Advances in Information Systems (35:4), pp. 6-102.

Dubé, L., and Paré, G. 2003. "Rigor in Information Systems Positivist Case Research: Current Practices, Trends, and Recommendations," MIS Quarterly (27:4), pp. 597-635.

Eisenhardt, K. M. 1985. "Control: Organizational and Economic Approaches," Management Science (31), pp. 134-149.

Eisenhardt, K. M. 1989. "Building Theories from Case Study Research," Academy of Management Review (14:4), pp. 532-550.

Erickson, J. M., and Ranganathan, C. 2006. "Project Management Capabilities: Key to Application Development Offshore Outsourcing," in Proceedings of the $39^{\text {th }}$ Hawaii International Conference on System Sciences, Los Alamitos, CA: IEEE Computer Society Press.

Erramilli, M. K., and Rao, C. P. 1993. 'Service Firms' International Entry-Mode Choice: A Modified Transaction-Cost Analysis Approach," Journal of Marketing (57), July, pp. 19-38.

Ethiraj, S. K., Kale, P., Krishnan, M. S., and Singh, J. 2005. "Where Do Capabilities Come From and How Do They Matter? A Study in the Software Services Industry," Strategic Management Journal (26:1), pp. 25-45.
Fama, E. F. 1980. "Agency Problems and the Theory of the Firm," Journal of Political Economy (88), pp. 288-307.

Foss, N. J. 1993. "Theories of the Firm: Contractual and Competence Perspectives," Journal of Evolutionary Economics (3), pp. 127-144.

Fransman M. 1994. "Information Knowledge, Vision and the Theory of the Firm," Industrial and Corporate Change (3:3), pp. 713-757.

Gattignon, H., and Anderson, E. 1988. "The Multinational Corporation's Degree of Control Over Foreign Subsidiaries: An Empirical Test of a Transaction Cost Explanation," Journal of Law, Economics, and Organization (4), Fall, pp. 305-336.

Ghoshal, S., and Moran, P. 1996. "Bad for Practice: A Critique of the Transaction Cost Theory," The Academy of Management Review (21:1), pp. 13-47.

Goles, T. 2003. "Vendor Capabilities and Outsourcing Success: A Resource-Based View," Wirtschaftsinformatik (45:2), pp. 199-206.

Gopal, A., Mukhopadhyay, T., and Krishnan, M. S. 2002. "The Role of Software Processes and Communication in Offshore Software Development," Communications of the ACM(45:4), pp. 193-200.

Gopal, A., Sivaramakrishnan, K., Krishnan, M. S., and Mukhopadhyay, T. 2003. "Contracts in Offshore Software Development: An Empirical Analysis," Management Science (49:12), pp. 1671-1683.

Grant, R. M. 1996. "Toward a Knowledge-Based Theory of the Firm," Strategic Management Journal (17), Winter Special Issue, pp. 109-122.

Grover, V., Cheon, M. ., and Teng, J. T. C. 1996. "The Effect of Service Quality and Partnership on the Outsourcing of Information Systems Functions," Journal of Management Information Systems (12:4), pp. 89-116.

Gupta, A., and Govindarajan, V. 2000. "Knowledge Flows Within Multinational Corporations," Strategic Management Journal (21), pp. 473-496.

Hart, O., and Moore, J. 1990. "Property Rights and the Nature of the Firm," Journal of Political Economy (98), pp. 1119-1158.

Hatch, P. J. 2004. "Offshore 2005 Research: Preliminary Findings and Conclusions," Ventoro Institute (available online at http://www.ventoro.com/Offshore2005ResearchFindings.pdf).

Heeks, R., Krishna, S., Nicholson, B., and Sahay, S. 2001. "Synching or Sinking: Trajectories and Strategies in Global Software Outsourcing Relationships," IEEE Software Special Issue (18:2), pp. 54-60.

Hill, C. W. L. 1990. "Cooperation, Opportunism, and the Invisible Hand: Implications for Transaction Cost Theory," Academy of Management Review (15:3), pp. 500-513.

Hirschheim, R., George, B., and Wong, S. F. 2004. "Information Technology Outsourcing: The Move Towards Offshoring," Indian Journal of Economics and Business, Special Issue, pp. 103-124.

Hirschheim, R., Loebbecke, C., Newman, M., and Valor, J. 2005. "Offshoring and its Implications for the Information Systems Discipline," in Proceedings of the $26^{\text {th }}$ International Conference on Information Systems, D. Avison, D. Galletta, and J. I. DeGross (eds.), Las Vegas, December 11-14, pp. 1003-1018. 
Hofstede, G. 1980. Culture's Consequences, International Differences in Work-Related Values (Abridged ed.), Beverly Hills, CA: Sage Publications.

Holsti, O. R. 1969. Content Analysis for the Social Sciences and Humanities, Reading, MA: Addison-Wesley.

Huberman, M. A., and Miles, M. B. 1994. "Data Management and Analysis Methods," in Handbook of Qualitative Research, N. K. Denzin and Y. S. Lincoln (eds.), Thousand Oaks, CA: Sage Publications, pp. 428-444.

Hui, C. H., and Triandis, H. C. 1986. "Individualism-Collectivism: A Study of Cross-Cultural Research," Journal of Cross-Cultural Psychology (17), pp. 222-248.

Joshi, A. W., and Stump, R. L. 1999. "The Contingent Effect of Specific Investments on Joint Action in Manufacturer-Supplier Relationships: An Empirical Test of the Moderating Role of Reciprocal Asset Investments, Uncertainty, and Trust," Journal of the Academy of Marketing Science (27:3), pp. 291-305.

Keller, E. 1982. Management in Fremden Kulturen, Bern: Haupt. Khan, N., Currie, W. L., Weerakkody, V., and Desai, B. 2003. "Evaluating Offshore IT Outsourcing in India: Supplier and Customer Scenarios," in Proceedings of the $36^{\text {th }}$ Annual Hawaii International Conference on System Sciences, Los Alamitos, CA: IEEE Computer Society Press.

Kirsch, L. J. 1997. "Portfolios of Control Modes and IS Project Management," Information Systems Research (8:3), pp. 215-239.

Kliem, R. 2004. "Managing the Risks of Offshore IT Development Projects," Information Systems Management, Summer, pp. 22-27.

Knudsen, C. 1995. "Theories of the Firm, Strategic Management, and Leadership," in Resource-Based and Evolutionary Theories of the Firm: Towards a Synthesis, C. A. Montgomery (ed.), Boston: Kluwer Academic Publishers, pp. 179-217.

Ko, D.-G., Kirsch, L. J., and King, W. R. 2005. "Antecedents of Knowledge Transfer from Consultants to Clients in Enterprise System Implementations," MIS Quarterly (29:1), pp. 59-85.

Kogut, B., and Singh, H. 1988. "The Effect of National Culture on the Choice of Entry Mode," Journal of International Business Studies (19:41), pp. 1-32.

Krishna, S., Sahay, S., and Walsham, G. 2004. "Managing CrossCultural Issues in Global Software Outsourcing," Communications of the ACM (47:4), pp. 62-66.

Kumar, N., Stern, L. W., and Anderson, J. C. 1993. "Conducting Interorganizational Research Using Key Informants," Academy of Management Journal (36), pp. 1633-1651.

Kumar, S., and Seth, A. 1998. "The Design of Coordination and Control Mechanisms for Managing Joint Venture-Parent Relationships," Strategic Management Journal (19), pp. 579-599.

Lacity, M. C., and Willcocks, L. P. 1998. "An Empirical Investigation of Information Technology Sourcing Practices: Lessons from Experience," MIS Quarterly (22:3), pp. 363-408.

Lammers, M., Löhndorf, N., and Weitzel, T. 2004. "Strategic Sourcing in Banking: A Framework," in Proceedings of the 12 European Conference on Information Systems, T. Leino, T. Saarinen, and S. Klein (eds.), Turku, Finland, June 14-16, pp. 986-998.

Lancellotti, R., Schein, O., Spang, S., and Stadler, V. 2003. "ICT and Operations Outsourcing: Insights from an Interview-Based Pan-Eurpoean Survey," Wirtschaftsinformatik (45:2), pp. 131-141.
Lane, P. J., Koka, B. R., and Pathak, S. 2006. "The Reification of Absorptive Capacity: A Critical Review and Rejuvenation of the Construct," Academy of Management Review (31:4), pp. 833-863.

Lee, A. S. 1991. "Integrating Positivist and Interpretive Approaches to Organizational Research," Organization Science (2:4), pp. 342-365.

Levina, N. 2005. "Collaborating Across Boundaries in a Global Economy: Do Organizational Boundaries and Country Contexts Matter?," in Proceedings of $27^{\text {th }}$ International Conference on Information Systems, D. Straub, S. Klein, W. Haseman, and C. Washburn (eds.), Milwaukee, WI, December 10-13, pp. 527-542.

Lewin, A. Y., and Peeters, C. 2006. "Offshoring Work: Business Hype or the Onset of Fundamental Transformation," Long Range Planning (39), pp. 221-239.

Malhotra, A., Gosain, S., and El Sawy, O. A. 2005. "Absorptive Capacity Configurations in Supply Chains: Gearing for PartnerEnabled Market Knowledge Creation," MIS Quarterly (29:1), pp. 145-188.

Malone, T. W., and Crowston, K. 1994. "The Interdisciplinary Study of Coordination," ACM Computing Surveys (26:1), pp. 87-119.

Miles, M. B., and Huberman, M. A. 1994. Qualitative Data Analysis: An Expanded Sourcebook, Thousand Oaks, CA: Sage Publications.

Mirani, R. 2007. "Procedural Coordination and Offshored Software Tasks: Lessons from Two Case Studies," Information \& Management (44), pp. 216-230.

Murdock, G. 1940. "The Cross-Cultural Survey," American Sociological Review (5:3), pp. 361-370.

Nelson, R. R., and Winter, S. G. 1982. An Evolutionary Theory of Economic Change, Cambridge, MA: Belknap Press.

Nicholson, B., and Sahay, S. 2001. "Some Political and Cultural Implications of the Globalisation of Software Development: Case Experience from UK and India," Information and Organisation (11:1), pp. 25-43.

Nidumolu, S. 1995. "The Effect of Coordination and Uncertainty on Software Project Performance: Residual Performance Risk as an Intervening Variable," Information Systems Research (6:3), pp. 191-219.

Niederman, F. 2005. "International Business and MIS Approaches to Multinational Organizational Research: The Cases of Knowledge Transfer and IT Workforce Outsourcing," Journal of International Management (11), pp. 187-200.

Nonaka, I. 1994. "Dynamic Theory of Organizational Knowledge Creation," Organization Science (5:1), pp. 14-37.

Nonaka, I., and Konno, N. 1998. "The Concept of 'Ba': Building a Foundation for Knowledge Creation," California Management Review (40:3), pp. 40-54.

Noorderhaven, N. G. 1996. “Opportunism and Trust in Transaction Cost Economics," in Transaction Cost Economics and Beyond, J. Groenewegen (ed.), Boston: Kluwer Academic Publishers, pp. 105-128.

Olson, G. M., and Olson, J. S. 2000. "Distance Matters," Human Computer Interaction (15:2/3), pp. 139-178.

Ouchi, W. 1979. "A Conceptual Framework for the Design of Organizational Control Mechanisms," Management Science (25), pp. 833-848. 
Ouchi, W. 1980. “Markets, Bureaucracies and Clans," Administrative Science Quarterly (25), pp. 129-142.

Overby, S. 2003. "The Hidden Costs of Offshore Outsourcing," CIO Magazine, September 1 (available online at http://www. cio.com/article/29654/The_Hidden_Costs_of_Offshore_ Outsourcing).

Penrose, E. T. 1959. The Theory of the Growth of the Firm, New York: Blackwell.

Qu, Z., and Brocklehurst, M. 2003. "What Will it Take for China to Become a Competitive Force in Offshore Outsourcing? An Analysis of the Role of Transaction Costs in Supplier Selection," Journal of Information Technology (18), pp. 53-67.

Quinn Patton, M. 2002. Qualitative Research and Evaluation Methods, Thousand Oaks, CA: Sage Publications.

Ramarapu, N., and Parzinger, M. J. 1997. "Issues in Foreign Outsourcing," Information Systems Management (14:2), pp. 27-31.

Rao, M. T. 2004. "Key Issues for Global IT Sourcing: Country and Individual Factors," Information Systems Management, Summer, pp. 16-21.

Rindfleisch, A., and Heide, J. B. 1997. "Transaction Cost Analysis: Past, Present, and Future Applications," Journal of Marketing (61:4), pp. 30-54.

Roberts, C., and Wasti, S. A. 2002. "Organizational Individualism and Collectivism: Theoretical Development and an Empirical Test of a Measure," Journal of Management (28:4), pp. 544-566.

Robillard, P. N. 1999. "The Role of Knowledge in Software Development," Communications of the ACM (42:1), pp. 87-92.

Rottman, J. W., and Lacity, M. C. 2004 . "Twenty Practices for Offshore Sourcing," MIS Quarterly Executive (3:3), pp. 117-130.

Rus, I., and Lindvall, M. 2002. "Knowledge Management in Software Engineering," IEEE Software (19:3), pp. 26-38.

Sabherwal, R., and Becerra-Fernandez, I. 2005. "Integrating Specific Knowledge: Insights From the Kennedy Space Center," IEEE Transactions on Engineering Management (52:3), pp. 301-315.

Sabherwal, R., and Choudhury, V. 2006. "Governance of Remotely Outsourced Software Development: A Comparison of Client and Vendor Perspectives," in Information Systems Outsourcing: Enduring Themes, New Perspectives, and Global Challenges, R. Hirschheim, A. Heinzl and J. Dibbern (eds.), Berlin: Springer-Verlag, pp. 187-222.

Scarbrough, H. 1998. "The External Acquisition of Information Systems Knowledge," in Strategic Sourcing of Information Systems, L. P. Willcocks and M. C. Lacity (eds.), Chichester, UK: John Wiley \& Sons 1998, pp. 137-161.

Schaaf, J. 2004. “Offshoring: Globalisation Wave Reaches Services Sector," Deutsche Bank Research Economics (45), September 27, pp. 2-15 (available online at http://www.dbresearch.com/).

Sherif, K., Zmud, R. W., and Browne, G. J. 2006. "Managing Peerto-Peer Conflicts in Disruptive Information Technology Innovations: The Case of Software Reuse," MIS Quarterly (30:2), pp. 339-356.

Simon, H. A. 1957. Models of Man: Social and Rational, New York: John Wiley \& Sons.

Sobol, M. G., and Apte, U. M. 1995. "Domestic and Global Outsourcing Practices of America's Most Effective IS Users," Journal of Information Technology (10), pp. 269-280.
Sobrero, M., and Roberts, E. B. 2001. "The Trade-Off between Efficiency and Learning in Interorganizational Relationships for Product Development," Management Science (47:4), pp. 493-511.

Sommerville, I. 2004. Software Engineering 7, Reading, MA: Addison-Wesley.

Stake, R. E. 2006. Multiple Case Study Analysis, New York: Guilford Press.

Tiwana, A. 2003. "Knowledge Partitioning in Outsourced Software Development: A Field Study,"in Proceedings of the $24^{\text {th }}$ International Conference on Information Systems, S. T. March. A. Massey, and J. I. DeGross (eds.), Seattle, WA, December 14-17, pp. 259-270.

Tiwana, A. 2004. "Beyond the Black-Box. Knowledge Overlaps in Software Outsourcing," IEEE Software, September/October, pp. 51-58.

Van de Ven, A. H., Delbecq, A. L., and Koenig, Jr., R. 1976. "Determinations of Coordination Modes within Organizations," American Sociological Review (41:3), pp. 322-338.

Wernerfelt, B. 1984. "A Resource-Based View of the Firm," Strategic Management Journal (5), pp. 171-180.

White, S., and Lui, S. S.-Y. 2005. "Distinguishing Costs of Cooperation and Control in Alliances," Strategic Management Journal (26), pp. 913-932.

Williamson, O. E. 1975. Markets and Hierarchies, Analysis and Antitrust Implications: A Study in the Economics of Internal Organization, New York: Free Press.

Williamson, O. E. 1981. "The Economics of Organization: The Transaction Cost Approach," American Journal of Sociology (87:3), pp. 548-577.

Williamson, O. E. 1985. The Economic Institutions of Capitalism: Firms, Markets, Relational Contracting, New York: Free Press.

Williamson, O. E. 1991. "Strategizing, Economizing, and Economic Organization," Strategic Management Journal (12), pp. 75-94.

Williamson, O. E. 1992. "Markets, Hierarchies, and the Modern Corporation: An Unfolding Perspective," Journal of Economic Behavior and Organization (17), pp. 335-352.

Yin, R. K. 2003. Case Study Research: Design and Method (3 $3^{\text {rd }}$ ed.), Thousand Oaks, CA: Sage Publications.

Zatolyuk, S., and Allgood, B. 2004. "Evaluating a Country for Offshore Outsourcing: Software Development Providers in the Ukraine," Information Systems Management (21:3), pp. 28-33.

\section{About the Authors}

Jens Dibbern is an assistant professor in Information Systems at the School of Business at the University of Mannheim, Germany. He received his $\mathrm{Ph} . \mathrm{D}$. in information systems from the University of Bayreuth, Germany, in 2003 and received the Alcatel SEL dissertation award for outstanding performance. His research has focused on outsourcing and the industrialization of application software services. His papers have appeared in WIRTSCHAFTSINFORMATIK, Zeitschrift für Betriebswirtschaft, and The Data Base for Advances in Information Systems. He serves as a senior editor of Data Base. 
Jessica Winkler is a Ph.D. student in Information Systems at the School of Business at the University of Mannheim, Germany. In 2005, she successfully completed her studies in Business Administration at the University of Mannheim, Germany, during which she also spent an academic year abroad at the University of Massachusetts and Amherst College. Her research focus is on offshore outsourcing and the internationalization of software service providers. She receives support from the German Ministry of Education and Research and has published in WIRTSCHAFTSINFORMATIK.

Armin Heinzl is Professor and Chair of Business Administration and Information Systems at the University of Mannheim, Germany.
His research and teaching interests are in the areas of process technologies, information systems outsourcing, and collaborative software engineering. He has held visiting positions at Harvard University, the University of California, Berkeley, and the University of California, Irvine. His papers have appeared in WIRTSCHAFTSINFORMATIK, Zeitschrift für Betriebswirtschaft, Die Betriebswirtschaft, Information Systems and E-Business Management, Journal of Organizational Computing and E-Commerce, and Evolutionary Computation. He is a member of the editorial board of the journal WIRTSCHAFTSINFORMATIK and a department editor for Zeitschrift für Betriebswirtschaft.

\section{Appendix A}

\section{Attributes Used to Assess the FINANCE Projects (based on Dubé and Paré 2003)}

\begin{tabular}{|c|c|}
\hline \multicolumn{2}{|l|}{ Research Design } \\
\hline Nature of own study & Positivist, explanatory study with some exploratory elements (see also Lee 1991). \\
\hline Clear research questions & Yes. \\
\hline $\begin{array}{l}\text { A priori specification of } \\
\text { constructs }\end{array}$ & Yes, due to explanatory character. \\
\hline Clean theoretical slate & No, propositions were formulated a priori due to explanatory nature. \\
\hline Theory of interest & Transaction cost economics and knowledge-based view. \\
\hline Rival theories included & $\begin{array}{l}\text { Yes, rival explanations of TCE versus KBV were examined regarding the impact of } \\
\text { client-specific knowledge on control and coordination costs. }\end{array}$ \\
\hline Multiple case design & Yes, one organization, six projects; every project represents a case. \\
\hline Replication logic & Both theoretical and literal replication logic. \\
\hline Unit of analysis & $\begin{array}{l}\text { Six offshored projects which are well stated and well documented; the unit of analysis is } \\
\text { consistent with the boundaries of the theories tested. } \\
\text { A global German financial services provider has been chosen since it is an early mover } \\
\text { in IT offshoring and since we wanted to incorporate a setting with a potential language } \\
\text { barrier; for both countries, English is not the mother language. }\end{array}$ \\
\hline Pilot case & Not conducted, since it is recommended for studies with a highly exploratory nature. \\
\hline Team-based research & Yes. \\
\hline Different roles of investigators & $\begin{array}{l}\text { First author and research scholar undertook data collection. } \\
\text { Second author and first author coded and interpreted the data independently. } \\
\text { Third author reconciled coding and interpretation differences. }\end{array}$ \\
\hline
\end{tabular}




\begin{tabular}{|c|c|}
\hline \multicolumn{2}{|l|}{ Context Description } \\
\hline Detailed site description & Yes. \\
\hline Case period & $\begin{array}{l}\text { The case material was collected during a period of } 6 \text { months with several onsite visits } \\
\text { and follow-up phone calls. }\end{array}$ \\
\hline Longitudinal design & No, not applicable. \\
\hline $\begin{array}{l}\text { Time spent onsite by the } \\
\text { researchers }\end{array}$ & $\begin{array}{l}\text { Yes, for setting up the case study design with top management and for conducting } \\
\text { interviews and for presenting final results. }\end{array}$ \\
\hline Nature of data collection & Retrospective. \\
\hline \multicolumn{2}{|c|}{ Elucidation of Data Collection Process } \\
\hline $\begin{array}{l}\text { Multiple data collection } \\
\text { methods }\end{array}$ & $\begin{array}{l}\text { Yes; data was solicited from different stakeholders via interviews; official project } \\
\text { documentation from the client organization were fully available and added into the } \\
\text { analysis. }\end{array}$ \\
\hline $\begin{array}{l}\text { Qualitative and quantitative } \\
\text { data }\end{array}$ & Qualitative only. \\
\hline Data Triangulation & Yes, for different stakeholders and sources. \\
\hline Case Study Protocol & Yes. \\
\hline Case Study Database & Yes, using the software package NVIVO. \\
\hline \multicolumn{2}{|c|}{ Data Collection Methods Applied } \\
\hline Interviews & Yes. \\
\hline Documentation & Yes. \\
\hline Observation & No. \\
\hline Questionnaires & Yes, in the form of interview guides. \\
\hline Artifacts & No, only examination of the software systems that were offshored. \\
\hline Time Series & No. \\
\hline Sampling Strategy & $\begin{array}{l}\text { Combination of convenient sample and quota sample (three projects of IS development } \\
\text { and three projects of IS maintenance). }\end{array}$ \\
\hline \multicolumn{2}{|c|}{ Elucidation of Data Analysis Process } \\
\hline Field notes & Yes. \\
\hline Coding & Yes. \\
\hline Data displays & Yes. \\
\hline $\begin{array}{l}\text { Flexible and opportunistic } \\
\text { process }\end{array}$ & Yes. \\
\hline Logical chain of evidence & Yes. \\
\hline Empirical testing & Yes. \\
\hline Explanation building & Yes. \\
\hline Time series analysis & No. \\
\hline $\begin{array}{l}\text { Searching for cross-case } \\
\text { patterns }\end{array}$ & Yes. \\
\hline Use of natural controls & No. \\
\hline Quotes (evidence) & Yes. \\
\hline Project reviews & Yes. \\
\hline $\begin{array}{l}\text { Comparison with extant } \\
\text { literature }\end{array}$ & Yes, especially with supporting literature. \\
\hline
\end{tabular}




\section{Appendix B}

\section{High-Level Interview Guideline}

0) Introduction

0.1 When did you become involved in this project?

0.2 What is your task in this team? Which aspects do you concentrate on?

1) Decision process and project characteristics

1.1 Why did FINANCE choose to offshore this project?

1.2 Which characteristics of this project make it suitable for offshore outsourcing?

1.3 Which parts of the IS function remained in-house?

2) Requirements and Realization

2.1 How much domain or firm-specific know-how is needed for the outsourced task?

2.2 How are requirements designed and communicated to the vendor?

2.3 How many of the issues arising are due to incomplete or vague requirements specification?

3) Transition phase

3.1 How did the knowledge transfer take place?

3.2 Who was responsible for providing the specifications?

4) Delivery phase

4.1 How is the internal and offshore team structure of this project organized?

4.2 What are the main mechanisms for managing this project?

4.3 How is your contract with the vendor specified and enacted?

4.4 Are there misunderstandings? What are the main reasons?

4.5 What are the main challenges in this project?

4.6 Has something changed in the service quality since the offshore outsourcing arrangement?

5) Outcome

5.1 How was the sourcing decision evaluated?

5.2 Were the expectations met?

5.3 Did unexpected additional costs arise?

5.4 Are you satisfied with the offshore outsourcing arrangement? 